\title{
Cytochrome P450 2J2: Potential Role in Drug Metabolism and Cardiotoxicity
}

\author{
Meetal Solanki, Amy Pointon, Barry Jones, and Karl Herbert \\ Department of Cardiovascular Sciences, University of Leicester, Clinical Sciences, Glenfield Hospital, Leicester (M.S., K.H.), and \\ Safety and ADME Translational Sciences Department, Drug Safety and Metabolism (A.P.), and DMPK, Oncology, IMED Biotech \\ Unit (B.J.), AstraZeneca, Cambridge, United Kingdom
}

Received October 13, 2017; accepted April 19, 2018

\section{ABSTRACT}

Drug-induced cardiotoxicity may be modulated by endogenous arachidonic acid (AA)-derived metabolites known as epoxyeicosatrienoic acids (EETs) synthesized by cytochrome P450 2J2 (CYP2J2). The biologic effects of EETs, including their protective effects on inflammation and vasodilation, are diverse because, in part, of their ability to act on a variety of cell types. In addition, CYP2J2 metabolizes both exogenous and endogenous substrates and is involved in phase 1 metabolism of a variety of structurally diverse compounds, including some antihistamines, anticancer agents, and immunosuppressants. This review addresses current understanding of the role of CYP2J2 in the metabolism of xenobiotics and endogenous AA, focusing on the effects on the cardiovascular system. In particular, we have promoted here the hypothesis that CYP2J2 influences drug-induced cardiotoxicity through potentially conflicting effects on the production of protective EETs and the metabolism of drugs.

\section{Introduction}

Drug-induced cardiotoxicity affects all components and functions of the cardiovascular system. It is characterized by changes in electrocardiographic (ECG) waveform morphology, hemodynamics, pathologic damage to the myocardium and vasculature, and changes in blood function (Laverty et al., 2011). Cardiotoxicity is a major cause of attrition in preclinical and clinical drug development and may be attributed to numerous mechanisms (Pointon et al., 2013). Drugexerting effects on the cardiovascular system have been shown to change heart contractility, cardiac rhythm, blood pressure, and ischemia (Feenstra et al., 1999). Antihistamines such as astemizole and terfenadine cause abnormalities in ECG wave intervals, such as an increase in QT interval, leading to torsades de pointes (TdP) (Zhou et al., 1999; Lu et al., 2012). The anticancer drug doxorubicin (DOX), however, causes oxidative stress that results in structural damage to the heart, leading to heart failure (Chatterjee et al., 2010). Whereas astemizole exerts it effect primarily on cardiomyocytes, DOX also affects ancillary cells such as fibroblasts, endothelial cells, and vascular smooth muscle cells, disrupting the structure and function of vascular smooth muscle cells and inducing a profibrotic phenotype in fibroblasts (Chatterjee et al., 2010).

A.P. and B.J. are employees and shareholders of AstraZeneca. M.S. is in receipt of a Biotechnology and Biological Sciences Research Council (BBSRC)-funded PhD CASE award in collaboration with AstraZeneca [Grant BB/M503368/1].

https://doi.org/10.1124/dmd.117.078964.
This review focuses on cytochrome P450 (P450) 2J2 (CYP2J2), which has been shown to modulate drug-induced cardiotoxicity (Zhang et al., 2009b). The biologic role of CYP2J2 appears to relate primarily to its metabolism of arachidonic acid (AA) to cardioprotective epoxyeicosatrienoic acids (EETs). We present evidence in this review to support the proposal that a complex interplay between EET synthesis and drug metabolism by CYP2J2 exists. It is likely that EET synthesis often predominates and largely protects the cardiovascular system but that drugs might inhibit EET synthesis in a competitive or noncompetitive manner or that drug metabolism by CYP2J2, in the heart or elsewhere, might liberate cardiotoxic drug metabolites.

EETs possess pleiotropic biologic activities, including stimulation of angiogenesis, vasodilation, inhibition of vascular smooth muscle cell migration, protection against hypoxia-reperfusion injury, increased endothelial nitric oxide synthase expression and activity, and protection against DOX-induced cardiotoxicity (Larsen et al., 2007; Spector and Norris, 2007; Yang et al., 2009; Zhang et al., 2009b; Campbell and Fleming, 2010). Given these wide-ranging effects on the cardiovascular system, it is not surprising that EETs and CYP2J2 might modulate the pathogenesis of cardiovascular disease; however, understanding of the protective role of EETs during cardiotoxicity is relatively unexplored, suggesting that further studies on a range of cardiotoxic agents are worthwhile. CYP2J2 is also a drugmetabolizing enzyme and has been implicated in the biotransformation of a variety of drugs in the liver and other tissues (Michaud et al., 2010;

ABBREVIATIONS: AA, arachidonic acid; ANP, atrial natriuretic peptide; $\mathrm{BNP}, \beta$-natriuretic peptide; CYP2J2, cytochrome P450 2J2; DHET, dihydroxyeicosatrienoic acid; DOX, doxorubicin; ECG, electrocardiographic; EET, epoxyeicosatrienoic acid; 20-HEET, 20-hydroxyeicosatetraenoic acid; LPS, lipopolysaccharide; LVDP, left ventricular developed pressure; NDBD, $N$-desbutyldronedarone; NF- $\kappa$, nuclear factor- $\kappa$ B; P450, cytochrome P450; PI3K, phosphoinositide 3 kinase; ROS, reactive oxygen species; SEH, soluble epoxide hydrolase; SNP, single nucleotide polymorphisms; TdP, torsades de pointes; TNF, tumor necrosis factor. 


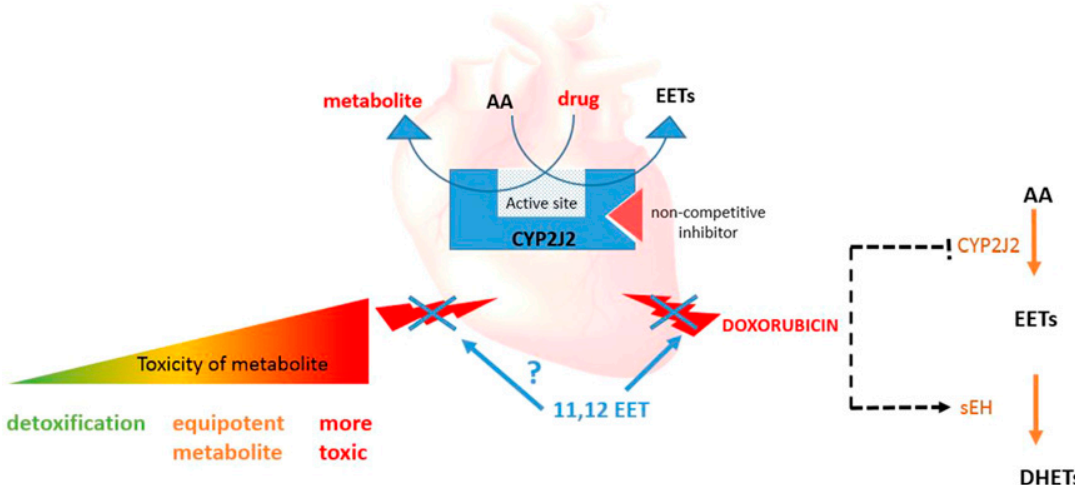

Fig. 1. Overview of hypothesized CYP2J2 functions in the heart. CYP2J2 has a role in drug metabolism in the heart, which may lead to either detoxification of drugs or cardiotoxicity. This could be counteracted by its epoxide activity by which it produces several protective molecules, including EETs. DOX inhibits production of EETs through inhibiting epoxygenase enzymes and increasing $\mathrm{sEH}$ mRNA production in rats; however, the addition of exogenous EETs protects against DOX toxicity in H9c2 cells (Zhang et al., 2009b). It may be proposed that the CYP2J2/EET pathway has a role in protecting against other drug-related toxicities within the heart. Furthermore, although there is little evidence regarding drug-AA interactions, the competition between drug substrates and AA may alter the balance of protective EETs and cardiotoxic compounds. Drugs such as dronedarone have been shown to inhibit CYP2J2 in a noncompetitive way and so inhibit EET formation in an in vitro system (From Karkhanis et al., 2016, 2017).
Xu et al., 2013). We also highlight how the balance between drug metabolism and protective EET formation may influence cardiotoxicity (Fig. 1).

\section{Role of CYP2J2 in Cardiovascular Biology}

The mRNA expression of CYP2J2 in humans is confined mainly to the cardiovascular system and liver, with predominant expression in the right ventricle of the heart (Michaud et al., 2010); however, mRNA has also been demonstrated in the kidney (Enayetallah et al., 2004); mRNA and protein in the lung (Zeldin et al., 1996), brain (Dutheil et al., 2009), gastrointestinal tract (Zeldin et al., 1997a), pancreas (Zeldin et al., 1997b), and some human carcinoma tissues at lower levels (Jiang et al., 2005). Discrepancies between CYP2J2 mRNA and protein expression have been found in the liver (Gaedigk et al., 2006); the consequence for the heart remains unknown. Additionally, multiple immunoreactive bands on Western blotting from extracts of adult human liver and heart have been reported. It has been hypothesized that these are uncharacterized isoforms of CYP2J2 (Wu et al., 1996; Gaedigk et al., 2006). These isoforms may possess similar or alternate activities to the main isoform of CYP2J2 and so warrant further study. Despite its elevated expression in the cardiovascular system compared with other tissues, the role of CYP2J2 in the metabolism of drugs in the heart is, to some extent, still unknown.

Results from a P450 mRNA screen showed that CYP2J2 is the predominant isoenzyme expressed in cardiomyocytes and human heart tissue (Fig. 2) (Evangelista et al., 2013). Furthermore, in line with these high levels of mRNA expression, CYP2J2 protein levels in human heart microsomes were approximately 50-fold greater than other P450 enzymes (Bylund et al., 2001; Evangelista et al., 2013). Evangelista and colleagues also established mRNA levels of the P450 enzyme CYP4F12 in the human heart. P450 enzymes belonging to the CYP4A and 4F subfamily produce 20-hydroxyeicosatetrenoic acid (20-HETE) from AA (Miyata et al., 2005; Harmon et al., 2006; Tang et al., 2010) and show increased expression in cardiovascular disease. 20-HETE has antagonistic effects toward EETs, exacerbating disease processes (Jenkins et al., 2009). It is largely unknown, however, how these other enzymes contribute to cardiovascular function and whether they have a role in cardiotoxicity.

In addition to cardiomyocytes, CYP2J2 expression has been observed in other cardiovascular cells. CYP2J2 is expressed in endothelial cells in a variety of vascular beds, including the coronary artery, aorta (Delozier et al., 2007), and varicose veins (BertrandThiebault et al., 2004). The presence of CYP2J2 in a variety of tissues and specific expression in the heart led to the hypothesis that CYP2J2 could contribute to endogenous tissue function. Although it is not well explored, the expression of CYP2J2 in endothelial cells, fibroblasts, and smooth muscle cells (Brutsaert, 2003; Deb and Ubil, 2014) could contribute to cardiotoxicity through drug metabolism, as well as protective effects through the formation of EETs.

In endothelial cells, mRNA for another epoxygenase, CYP2C9, is highly expressed compared with CYP2J2 (Delozier et al., 2007). Moreover, CYP2C9 mRNA levels were higher both in human aorta and coronary artery than were CYP2J2 and CYP2C8. Protein analysis further reflected this, as CYP2C9 expression was dominant compared with CYP2J2, and expression of CYP2C8 was not observed (Delozier et al., 2007). Although CYP2C9 can produce EETs, it has also been reported to generate damaging reactive oxygen species (ROS), which are regarded as proinflammatory mediators, increasing nuclear factor- $\kappa \mathrm{B}(\mathrm{NF}-\kappa \mathrm{B})$ activity (Fleming, 2001) and presumably leading to increased expression of proinflammatory cytokines, growth factors, and adhesion molecules, inducing an inflammatory phenotype and opposing the effects of CYP2J2 (Taniyama and Griendling, 2003).

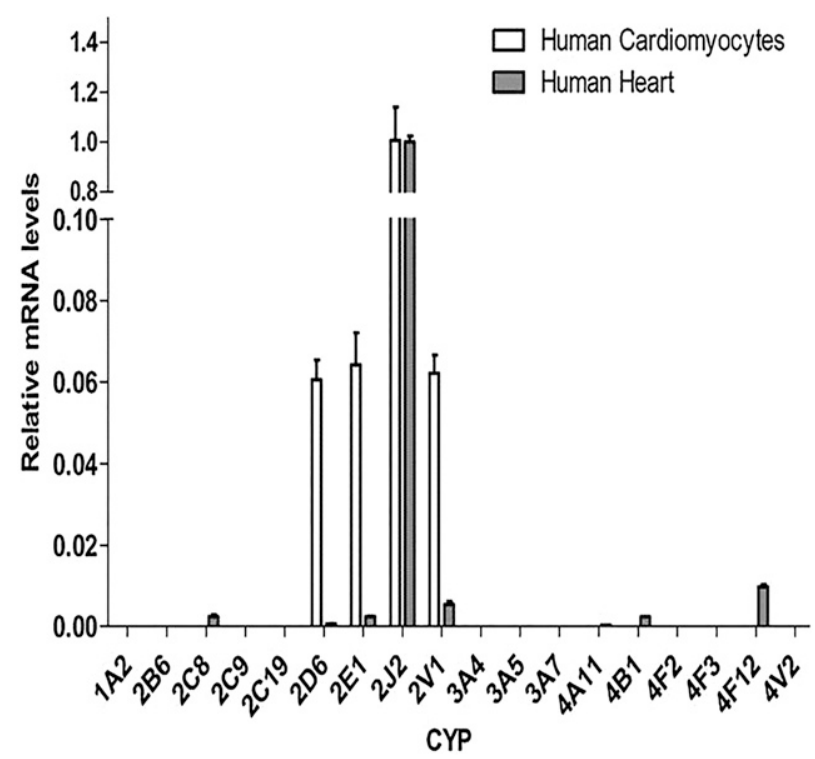

Fig. 2. Relative mRNA expression of P450s in human cardiomyocytes and human heart tissue and cardiomyocytes. Total RNA was extracted, and reverse-transcription polymerase chain reaction (RT-PCR) was carried out. The house keeper GusB was used a housekeeper gene, and $2^{\Delta \mathrm{CT}}$ calculation was used to quantitate CYP2J2 mRNA expression. Ten P450 enzymes were investigated, of which CYP2J2 had the highest expression (Reproduced, with permission, from Evangelista et al., 2013). 
CYP2J2 catalyzes the epoxidation of the double bonds of endogenous cellular AA to generate EETs (Fig. 3) (Zeldin et al., 1997a). Owing to the four double bonds of AA and the stereochemistry and regiochemistry associated with these bonds, eight EET isomers are possible: 5,6-EET (R/S), 8,9-EET(R/S), -11,12-EET(R/S), and 14,15-EET(R/S) (Xu et al., 2013). In vivo EETs are rapidly metabolized by soluble epoxide hydrolase (sEH) to dihydroxyeicosatrienoic acids (DHETs), which are less biologically active (Zhang et al., 2014). In addition to DHET formation, re-esterfication of EETs and incorporation into the phospholipid membrane for storage occur, allowing release and distribution (Bernstrom et al., 1992). Other relatively minor metabolism pathways of EETs have been described that involve cyclooxygenase, lipoxygenase, and P450 $\omega$-oxidase activities (Spector et al., 2004).
Soluble epoxide hydrolase may have significant biologic activity in a variety of tissues, including the liver, kidney, heart, spleen, endothelium, and mammary gland (Newman et al., 2005). Its deactivation of biologically protective EETs has led to the development of pharmacologic inhibitors of sEH (Liu et al., 2009; Hwang et al., 2013) and resulted in the first sEH inhibitor, AR9281, to begin phase 2a trials for the treatment of type 2 diabetes (Anandan et al., 2011), as well as recent introduction of sEH inhibitor, GSK225629, which is currently in phase 1 trials for the treatment of hypertension (Lazaar et al., 2016) and chronic obstructive pulmonary disease (Yang et al., 2017). Furthermore, several studies have shown that $\mathrm{sEH}$ plays an influential role in the development of myocardial hypertrophy (Xu et al., 2006) and atherosclerosis (Zhang et al., 2009a).
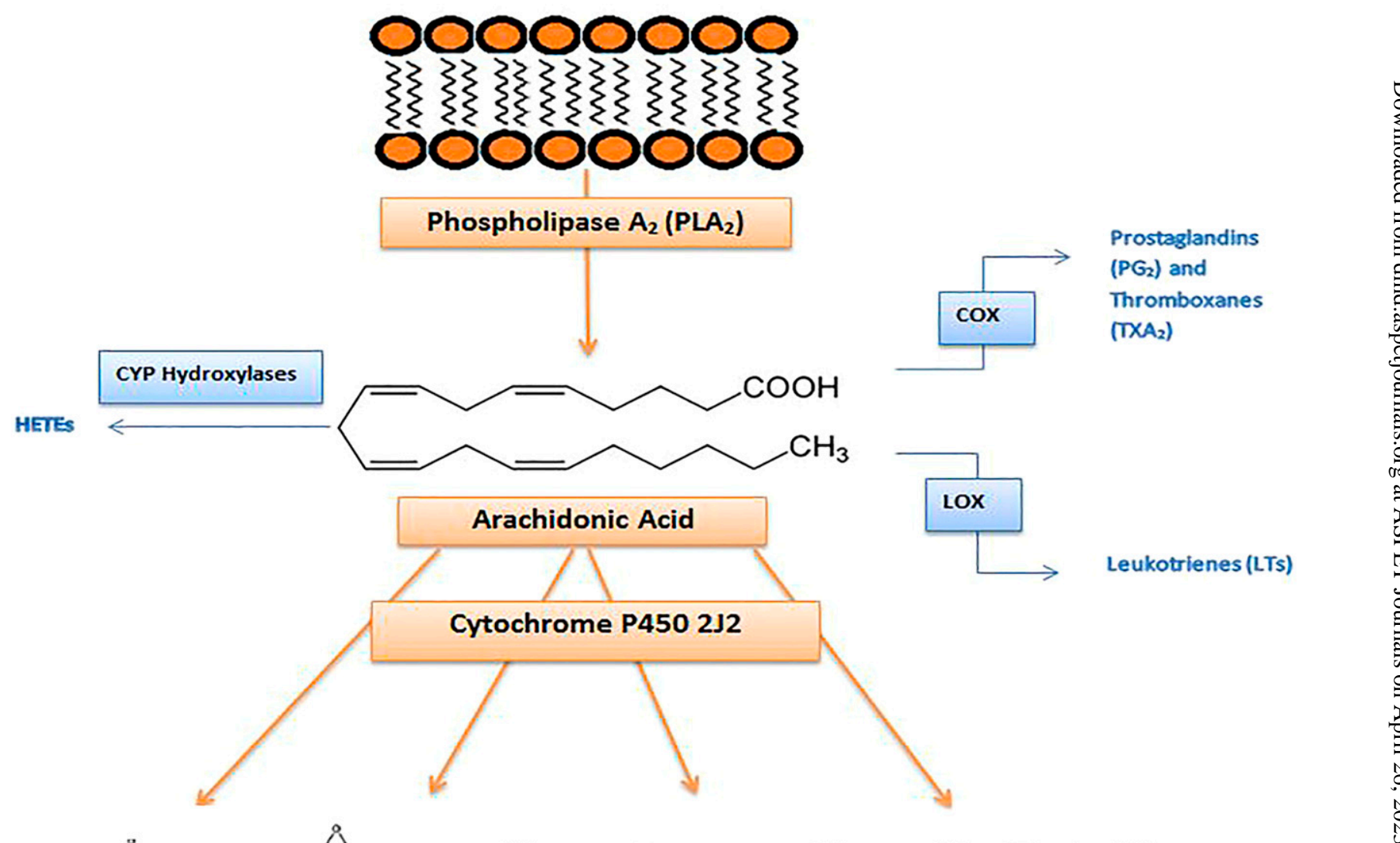
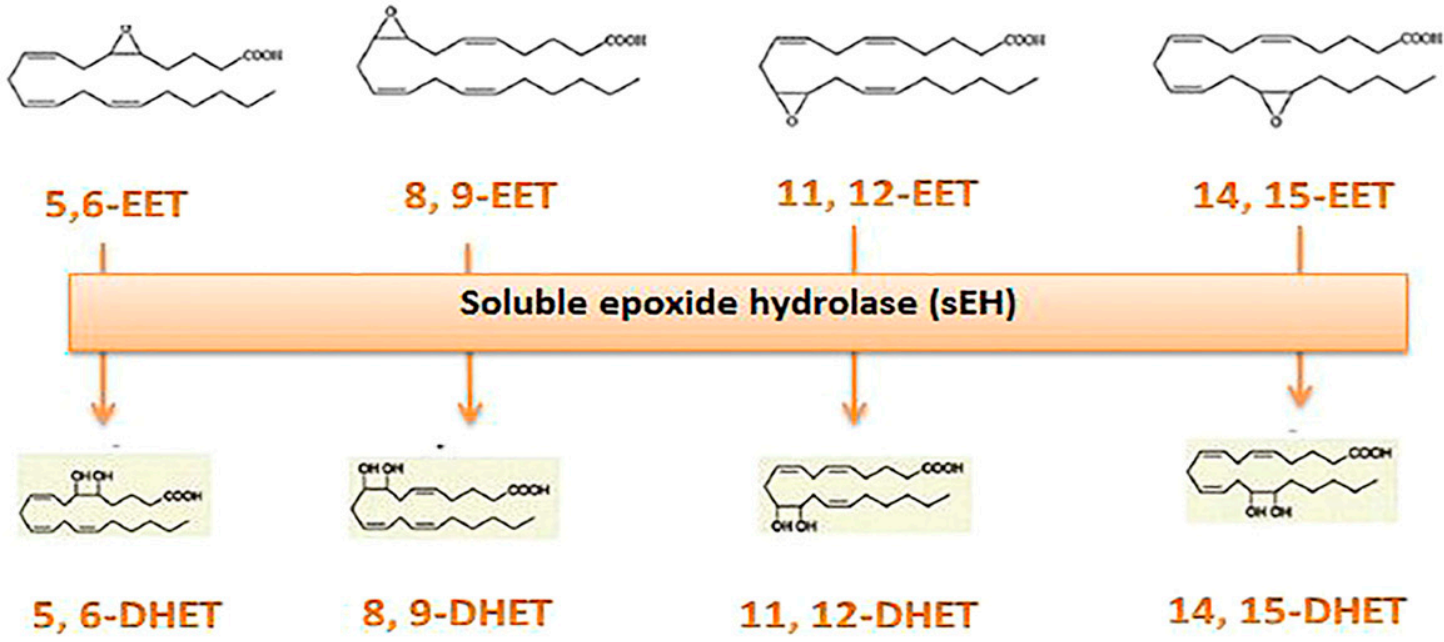

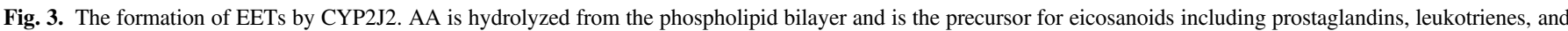
HETEs. Epoxidation by CYP2J2 leads to production of four different EETs, which can be deactivated by sEH to form DHETs. 
Investigation of the CYP2J2 epoxidation pathway in various tissues has provided evidence to support the idea that CYP2J2, and thus EETs, have a biologically protective role, and this is emphasized by the growing potential of $\mathrm{sEH}$ inhibitors. Investigation of these small-molecule inhibitors suggests a link between sEH inhibition and improved cardiovascular health and, given the high expression of CYP2J2 in the human heart, suggest a possible protective role for CYP2J2 in drug-induced cardiotoxicity.

Genetic Variation in Human CYP2J2. Epidemiologic studies conducted to examine variants in many P450 genes have found more than 2000 single nucleotide polymorphisms (SNPs) (Preissner et al., 2013). A number of these have been associated with disease. Within the Chinese population, a proximal promoter polymorphism $(-50 \mathrm{G}>\mathrm{T})$, rs890293 (CYP2J2*7), has been shown to alter CYP2J2 expression (Table 3). This mutation decreases binding of Sp1 transcription factor to the promoter region of CYP2J2. As Sp1 is responsible for regulating transcriptional basal activity, blocking it results in an $\sim 50 \%$ reduction in promoter activity and decreased expression of the CYP2J2 gene (Spiecker et al., 2004). This polymorphism may be involved in the pathogenesis of type 2 diabetes (Wang et al., 2010), Alzheimer disease (Yan et al., 2015), and chronic kidney disease and was negatively associated with cardiovascular diseases, including myocardial infarction (Jie et al., 2010), coronary artery disease (Zhu et al., 2013), and hypertension (Wu et al., 2007) within this population. On the other hand, studies conducted in the Swedish and German populations looking at cardiovascular risk found no susceptibility to hypertension, coronary artery disease, or stroke in carriers of the rs890293 polymorphism (Hoffmann et al., 2007; Fava et al., 2010), indicating that additional association studies may be required to elucidate the risk of this CYP2J2 polymorphism for cardiovascular disease. None of the other SNPs in CYP2J2 has been associated with disease (Table 3). Furthermore, no reported associations have been found between any CYP2J2 polymorphisms and cardiotoxicity, despite some of the variants having profound effects on enzyme expression or activity in vitro. Without further study, it is unknown whether CYP2J2 polymorphisms may be important in cardiotoxicity.

\section{CYP2J2/EETs in the Maintenance of Cardiovascular Health: a Potential Role in Cardiotoxicity?}

Cardiotoxicity can be viewed as a continuum of physiologic states that shares characteristics with cardiovascular disease. Consequently, understanding the role of CYP2J2 and EETs in cardiovascular disease can provide insight into their role in cardiotoxicity. It is widely recognized that many P450 enzymes are upregulated in failing hearts (Zordoky and El-Kadi, 2008a). The upregulation of CYP2J2 and EETs is protective in the heart. In the following sections, we discuss how CYP2J2 may play a role in the modulation of vascular inflammation, vascular tone, ischemia reperfusion injury, and cardiac hypertrophy.

Vascular Inflammation. Infiltration of inflammatory cells, particularly monocytes/macrophages, is an early event in and causal in the development of cardiovascular pathologies. Potent anti-inflammatory effects of CYP2J2 and EETs have been demonstrated both in vivo and in vitro. In vitro, synthetic EETs can reduce expression of many proinflammatory involved in the activation and adhesion of endothelial cells to leukocytes and leukocyte transmigration across the endothelium (Xu et al., 2011). For example, 11,12-EET suppresses the expression of adhesion molecules E-selectin and vascular cell adhesion molecule-1 in tumor-necrosis factor $\alpha$ (TNF- $\alpha$ )-induced human endothelial cells (Node et al., 1999). In addition to blocking the actions of TNF- $\alpha$, EETs (11, 12- and 8, 9-EET) have also been shown to inhibit basal TNF- $\alpha$ production in THP-1 cells, a model monocytic cell line (Bystrom et al.,
2011). EETs inhibit lipopolysaccharide (LPS)-induced macrophage polarization and reduce the expression of many proinflammatory cytokines while at the same time upregulating anti-inflammatory cytokine interleukin-10 in human embryonic kidney 293 cells overexpressing recombinant CYP2J2; these effects are likely mediated through downregulating NF- $k \beta$ and activation of peroxidase proliferationactivated receptors (Dai et al., 2015).

Studies in mouse models have further validated the effects of transgenic CYP2J2 and EETs in inflammation. Continuous infusion of 11,12-EET inhibited TNF- $\alpha$-induced endothelial vascular cell adhesion molecule-1 expression and mononuclear cell rolling and adhesion in mouse coronary arteries. In addition, in a CYP2J2 transgenic mouse model, expression of CYP2J2 in mice significantly reduced LPS-induced production of proinflammatory mediators interleukin-6 (IL-6), monocyte chemoattractant protein- 1 , E-selectin, and IL- $1 \beta$, as well as NF- $\kappa$ B activation and invasion of inflammatory cells in lung tissues (Potente et al., 2003). EETs inhibited phosphorylation of the NF- $\kappa$ B complex, preventing its translocation to the nucleus and hence transcriptional effects (Node et al., 1999). Transgenic CYP2J2 was also found to reduce angiotensin II-induced cardiac fibrosis and inflammation in mice, possibly though the inhibition of the NF-k $\beta$ pathway (Yang et al., 2015).

Inflammatory processes have been implicated in the development of atherosclerosis. CYP2J2 also protects against the production of atherosclerotic plaques in a transgenic mouse model of atherosclerosis (Liu et al., 2016). Apo-E-deficient mice and CYP2J2 transgenic mice were given a high-fat diet for 25 weeks. Histologic analysis of aorta samples identified fewer plaques on the luminal surface of the aorta in mice injected with CYP2J2 vector compared with wild-type. Analysis of lipids showed lower circulating triglyceride and cholesterol levels in transgenic mice. In addition, 11,-12 EET was shown to inhibit TNF- $\alpha-$ induced apoptosis in human umbilical vein cells through the activation of protein kinase $\mathrm{B}$ and FOXO1, which is downregulated in atherosclerotic aorta (Liu et al., 2016); however, it is challenging to ascertain whether these results are a direct outcome of CYP2J2-derived EETs or other protective molecules, for example, metabolites of EPA and DHA, and, moreover, to ascertain which of the EETs are responsible for the protective action.

Likewise, one of the hallmarks of some drug-induced cardiotoxicities is the increase in production of inflammatory mediators. For example, epirubicin, known to alter cardiac morphology, increases IL-6 and its soluble receptor sIL-6R, which have been shown to contribute to the pathophysiology of cardiomyopathy (Mercuro et al., 2007). It is possible that the anti-inflammatory effects of EETs could attenuate some of the myocardial damage mediated by elevated levels of these inflammatory mediators.

Vascular Tone. Maintenance of vascular tone is critical for cardiovascular function, particularly contributing to blood pressure regulation. EETs, in particular 11,12-EET, are also known as endothelial-derived hyperpolarizing factors and cause relaxation of rat coronary arteries, as well as renal and cerebral arteries of rats and rabbits (Campbell et al., 1996; Fisslthaler et al., 1999; Imig et al., 2001; Larsen et al., 2006; Dimitropoulou et al., 2007). EETs reduce vascular tone by attenuating calcium entry via voltage-sensitive channels, leading to hyperpolarization of vascular smooth muscle cells; however, EETs may also increase intracellular calcium concentration in endothelial cells by activation of $\mathrm{KCa}$ channels.

Although an increase in EETs has been shown to reduce vascular tone and protect against cardiovascular disease in animal models, it is still unknown how this protective pathway may influence cardiotoxicity.

Ischemia Reperfusion Injury. Ischemia-reperfusion injury can lead to accumulation of protective EETs after the release of fatty acids by 
membrane-bound phospholipases (Seubert et al., 2004). Increasing EETs in an sEH null mouse model showed limited mitochondrial damage after ischemia compared with wild-type (Akhnokh et al., 2016). EETs can enforce their cardioprotective effects through the activation of mitoK (ATP) and opening of the mitochondrial membrane permeability pore (Barau et al., 2015). Activation of this protective pathway by EETs maintains mitochondrial structure and function in CYP2J2 transgenic mice (Seubert et al., 2004). It is well known that mitochondrial ischemia reperfusion injury activates apoptosis. EETs inhibit proapoptotic pathways through the prosurvival enzyme phosphoinositide 3 kinase (PI3K) in rat cardiomyocytes (Isomoto et al., 2006).

Transgenic mice with endothelial cell-specific CYP2J2 expression showed that endothelial-derived EETs did not protect against cardiac ischemia; moreover, transgenic mice with enhanced endothelial expression of sEH showed no changes in left ventricular developed pressure (LVDP) and infarct size; however, transgenic mice with myocardial specific expression of CYP2J2 had increased recovery of LVDP and decreased infarct size after ischemia-reperfusion compared with wildtype. Furthermore, transgenic mice with expression of myocardial sEH showed no changes in LVDP and infarct size (Edin et al., 2011). These results add another layer of complexity to the protective capabilities of EETs and how EETs produced from different areas and cell types of the cardiovascular system may have varying effects.

Cardiac Hypertrophy. Cardiac hypertrophy is a prominent risk factor for heart failure and a strong predictor of adverse cardiovascular events (Zordoky and El-Kadi, 2008a). It is normally characterized by an increase in cardiomyocyte size, increased synthesis of $\beta$ natriuretic peptide (BNP), atrial natriuretic peptide (ANP), myosin, and actin accompanied by fibrosis and remodeling (Alsaad et al., 2013). Animal models have shown that during isoproterenol-induced cardiac hypertrophy, there is a decrease in protective EETs. Modulation of this process, that is, increasing the EET half-life by using sEH inhibitors, protected against the detrimental effects of cardiac hypertrophy, although the exact mechanism for this protection is yet to be determined. (Zordoky and El-Kadi, 2008a).

\section{Animal Homologs of CYP2J2 to Investigate Preclinical Drug- Induced Cardiotoxicity}

Before they can be used in humans, novel small molecules must be tested in both rodent and nonrodent in vivo models to assess for potential safety liabilities in major organs, including the heart. Many mammals possess homologs of the human CYP2J2 protein with varying sequence similarities, including the commonly used species for regulatory safety, pharmacology, and toxicology studies (in rodents, dogs, and monkeys) (Tables 1 and 2).

Compared with the single CYP2J2 gene in humans, mice have a cluster of CYP2J isoform genes. This subfamily is highly homologous: $62 \%-84 \%$ homology at the amino acid level compared with humans. Mice CYP2J isoforms are distributed in the liver, kidneys, intestine, brain, and lung and abundantly in the heart (Graves et al., 2013). All enzymes produced from the CYP2J cluster have similar substrate preference, but the products have a unique profile (Nelson et al., 2004). Compared with recombinant CYP2J2 microsomes, all isoforms have been shown to metabolize AA, albeit at a lower rate (Graves et al., 2013).

Mouse models are used to investigate cytochrome P450-dependent metabolism. Knockout and transgenic mice are used to study the metabolism pathways pertaining to a specific enzyme leading to toxicity. For example, knockout and humanized mouse models for CYP2E1 have been used to characterize acetaminophen hepatotoxicity (Gonzalez et al., 2015). Currently, transgenic mouse models for CYP2J have been created
TABLE 1

Amino acid sequence homology between human CYP2J2 and mammalian CYP2Js

Humans, monkeys, and dogs all have single isoforms for CYP2J2, whereas rodents (e.g., rats) have multiple isoforms, CYP2J3 and 2J4 the most similar to those in humans. Values are the percentage of sequence homology.

\begin{tabular}{lcccrr}
\hline & Human 2J2 & Monkey 2J2 & Dog 2J2 & \multicolumn{2}{c}{ Rat 2J3 2J4 } \\
\hline Human 2J2 & \multirow{2}{*}{100} & 95 & 79 & 72 & 76 \\
Monkey 2J2 & & 100 & 81 & 74 & 76 \\
Dog 2J2 & & & 100 & 72 & 72 \\
Rat 2J3 & & & 100 & 79 \\
Rat 2J4 & & & & 100 \\
\hline
\end{tabular}

to understand the biologic significance of EETs in disease; however, studies specifically addressing the role of CYP2J in the induction of toxicity have not yet been described. In vitro, mouse-derived HL-1 cell lines have limited cardiac morphologic, biochemical, and electrophysiologic properties compared with human adult cardiomyocytes; however, their expression of P450 enzymes has not been clearly investigated and so may offer a potential in vitro cardiac model for studying CYP2J.

The main rat homologs, CYP2J3 and CYP2J4, have $72 \%$ and $76 \%$ sequence similar to human CYP2J2, and have a similar tissue distribution to human. Furthermore, CYP2J3 is reported to be found primarily within atrial and ventricular myocytes (Wu et al., 1997; Zhang et al., 1997), whereas increased expression of CYP2J3 in the heart after ischemic postconditioning significantly increased EET generation (Wang et al., 2012), suggesting that CYP2J3 may have epoxygenase activity analogous to CYP2J2. Therefore, rat CYP2J3 may be the closest homologous enzyme to CYP2J2 in terms of distribution and epoxygenase activity and may be applicable to investigations of cardiotoxicity. Also, rat cardiac cell lines, such as rat myoblast H9c2 cells, have been used to investigate cardiac biology and toxicology; however, they lack key functional features of cardiomyocytes, exhibit a mainly skeletal muscle phenotype, and do not respond to electrical stimulation (Kimes and Brandt, 1976); however, they have recently been used to investigate the cardioprotective effects of drugs after oxidative damage (Zhou et al., 2016), thus suggesting the potential use of these cells in investigating the mechanisms of cardioprotection from druginduced cardiotoxicity.

In both dogs and monkeys, a single CYP2J isoform (CYP2J2) has been identified (Nelson, 2009). Monkey CYP2J2 has the greatest sequence similarity (95\%) to CYP2J2 in humans (Uno et al., 2007). Immunoquantification of cynomolgus CYP2J2 identified higher levels of protein in the monkey liver compared with the human liver (Uehara et al., 2015), as reflected in activity where there was a higher hepatic clearance of astemizole (Nishimuta et al., 2011), which has been shown to be a drug substrate for CYP2J2 (Uehara et al., 2015). To our knowledge, however, expression of CYP2J2 at the mRNA or protein level has not yet been quantified in the monkey or dog heart.

Cardiotoxicity encompass a variety of features, including changes in pathology, ECG, and hemodynamics. Therefore, some animal models may be recommended for investigating functional changes, whereas other models may be more suited to examining pathologic changes. For example, rats, which reflect the protective capabilities of CYP2J, would be acceptable for studying EETs; however, their use in predicting cardiotoxicity associated with ion channel inhibition is limited. Consequently, when selecting a suitable preclinical model system, both the potential ability to modulate CYP2J2 and the expected cardiac effects being risk assessed should be taken into consideration in selecting the most appropriate approach and species. Furthermore, although the dog has a single CYP2J2 isoform with high sequence similarity, more studies 
TABLE 2

CYP2J gene expressions in human and other mammalian tissues

Expression is quantified, whereby $(+)$ is low expression, $(++)$ is moderate expression and (+++) is high expression. Within the heart, human CYP2J2 has the highest level of RNA and protein expression. Rat CYP2J3 has high levels of protein and mouse CYP2J11 has high RNA expression in the heart, indicating that there are often discrepancies between RNA and protein expression in different homologs.

\begin{tabular}{|c|c|c|c|c|c|c|c|c|c|c|c|}
\hline & \multirow{2}{*}{$\frac{\text { Human }}{2 \mathrm{~J} 2}$} & \multicolumn{7}{|c|}{ Mouse } & \multirow{2}{*}{$\frac{\text { Monkey }}{2 \mathrm{~J} 2}$} & \multicolumn{2}{|c|}{ Rat } \\
\hline & & $2 \mathrm{~J} 5$ & $2 \mathrm{~J} 6$ & $2 \mathrm{~J} 8$ & $2 \mathrm{~J} 9$ & $2 \mathrm{~J} 11$ & $2 \mathrm{~J} 12$ & $2 \mathrm{~J} 13$ & & $2 \mathrm{~J} 3$ & $2 \mathrm{~J} 4$ \\
\hline Liver & & & ++ & + & & ++ & & & ++ & & \\
\hline RNA & ++ & + & & & & & & & & +++ & ++ \\
\hline Protein & ++ & ++ & & & & & & & & +++ & ++ \\
\hline Heart & & & + & & & & & + & + & & \\
\hline RNA & +++ & & & & & +++ & & & & + & \\
\hline Protein & +++ & & & & & + & & & & +++ & \\
\hline Small intestine & & & +++ & & & + & + & + & +++ & + & \\
\hline RNA & ++ & & & & & & & & & & +++ \\
\hline Protein & + & & & & & & & & & & +++ \\
\hline Lung & & + & + & & + & & & + & ++ & & + \\
\hline RNA & + & & & & & & & & & + & \\
\hline Protein & + & & & & & & & & & + & \\
\hline Kidney & & & ++ & & ++ & & & +++ & & & \\
\hline RNA & + & +++ & & +++ & & +++ & & & & + & \\
\hline Protein & ++ & +++ & & ++ & & +++ & & & & + & \\
\hline Brain & & & ++ & & & & +++ & + & & & \\
\hline RNA & + & & & + & +++ & & & & & & \\
\hline Protein & + & & & ++ & +++ & & & & & & \\
\hline Pancreas & & & & & & & & + & & ++ & \\
\hline RNA & + & & & & & & & & & & \\
\hline Protein & + & & & & & & & & & & \\
\hline Stomach & & & & & & & & + & & & \\
\hline RNA & & & & & & & & & & + & \\
\hline Protein & & & & & & & & & & + & \\
\hline Spleen & & & & & & + & + & + & & & \\
\hline RNA & & & & & & & & & & & \\
\hline Protein & & & & & & & & & & & \\
\hline Skeletal muscle & ++ & & & & & & & & & & \\
\hline RNA & & & & & & & & & & & \\
\hline Protein & & & & & & & & & & & \\
\hline
\end{tabular}

Adapted from Xu et al. (2013).

are required to fully determine whether the dog is the best model to study CYP2J2 from both cardiovascular biology and CYP2J2 perspectives (Table 3).

\section{Role of CYP2J2 in Xenobiotic Metabolism}

In the human liver, CYP2J2 protein comprises $1 \%$ to $2 \%$ of total $\mathrm{P} 450$ content, similar to that in the small intestine (1.4\%) (Paine et al., 2006) compared with CYP3A4, which constitutes $\sim 30 \%$ of total P450 content
(Michaels and Wang, 2014); however, as CYP3A4 expression is low in cardiac tissue, it is unlikely to contribute to drug metabolism within the heart (Chaudhary et al., 2009). Although not the most highly expressed P450 in the liver and intestine, CYP2J2 mediates drug biotransformation reactions with numerous exogenous substances. CYP2J2 is the primary enzyme involved in several metabolic reactions, including amiodarone 4-hydroxylation, astemizole O-demethylation, and ebastine hydroxylation (Matsumoto and Yamazoe, 2001; Matsumoto et al., 2002; Liu et al., 2006). For ebastine, CYP2J2 plays a superior role in first-pass

TABLE 3

CYP2J2 allelic variations in humans known to have changes in activity in vitro

Currently only a variation in the CYP2J2*7 allele has been shown to have associations with disease.

\begin{tabular}{|c|c|c|c|c|}
\hline Allele & cDNA/Gene & Enzyme Activity in Vitro & Association with Disease & References \\
\hline $\mathrm{CYP} 2 \mathrm{~J} 2 * 2$ & $427 \mathrm{~A}>\mathrm{G}$ & Reduced AA and LA metabolism & No known association with disease & King et al. (2002) \\
\hline $\mathrm{CYP} 2 \mathrm{~J} 2 * 3$ & $472 \mathrm{C}>\mathrm{T}$ & Reduced AA and LA metabolism & No known association with disease & King et al. (2002) \\
\hline CYP2J2*4 & $575 \mathrm{~T}>\mathrm{A}$ & Reduced AA metabolism & No known association with disease & King et al. (2002) \\
\hline CYP2J2*5 & $1024 \mathrm{G}>\mathrm{A}$ & $\begin{array}{l}\text { Produced wild type levels of AA and } \\
\text { LA metabolites }\end{array}$ & No known association with disease & King et al. (2002) \\
\hline CYP2J2*6 & $1210 \mathrm{~A}>\mathrm{T}$ & Reduced AA and LA metabolism & No known association with disease & King et al. (2002) \\
\hline CYP2J2*7 & $-50 \mathrm{G}>\mathrm{T}$ & $\begin{array}{l}\text { Reduced transcription due to loss of } \\
\text { Sp1 binding site }\end{array}$ & $\begin{array}{l}\text { Type } 2 \text { diabetes Alzheimer disease, } \\
\text { coronary artery disease, Ischemic } \\
\text { stroke }\end{array}$ & $\begin{array}{l}\text { King et al. (2002); Spiecker et al. (2004); } \\
\text { Wang et al. (2010, 2017); Zhu et al. (2013); } \\
\text { Yan et al. (2015) }\end{array}$ \\
\hline CYP2J $2 * 8$ & $934 \mathrm{G}>\mathrm{A}$ & Complete loss of enzymatic activity & No known association with disease & Lee et al. (2005) \\
\hline CYP2J2*9 & $1052 \mathrm{C}>\mathrm{T}$ & Enzymatic activity comparable to wild type & No known association with disease & Lee et al. (2005) \\
\hline CYP2J $2 * 10$ & $344 \mathrm{C}>\mathrm{T}$ & Reduced function protein & No known association with disease & Gaedigk et al. (2006) \\
\hline
\end{tabular}

AA, arachidonic acid; LA, linoleic acid.

Adapted from Berlin et al. (2011). 
intestinal metabolism to its pharmacologically active metabolite and less toxic carebastine. All three of these compounds are known cardiotoxins. Both astemizole and ebastine block the Kv11.1 (hERG) potassium channel, causing TdP and QT prolongation arrhythmias; however both amiodarone and astemizole metabolites are as toxic as the primary compound when metabolized (Matsumoto et al., 2002). Thus, the individual product profile of a compound resulting from CYP2J2 metabolism may lead to less toxic or equipotent metabolites and altered toxicity of these drugs within the heart.

A study in human liver microsomes identified eight novel substrates for CYP2J2 after screening 139 compounds, including marketed therapeutic agents. These chemical entities had wide structural diversity and ranged from small molecules like albendazole to larger complex structures such as cyclosporine (Lee et al., 2010). This diversity in drug substrates highlights how CYP2J2 may be vital in mediating drug responses and gives a glimpse into the similarity between CYP2J2 and other P450 enzymes of similar function. CYP2J2 and CYP3A4 share several substrates, including antihistamines (terfenadine, astemizole, and ebastine), anticancer drugs (DOC and tamoxifen), and immunosuppressants (cyclosporine); a list of known CYP2J2 substrates is shown in Table 4. In silico approaches suggest structural similarity between CYP2J2 and CYP3A4, and a comparison of active sites showed homology; however, further examination shows slight differences in structural geometry. CYP2J2 has a more cylindrical shape and is narrower than CYP3A4 as the $\beta-4$ part of the protein is smaller and has a loop that inserts into the active site restricting metabolism (Lee et al., 2010).

Biotransformation studies looking at the metabolism profile of CYP2J2 and CYP3A4 showed that CYP2J2 produced numerous metabolites, many of which were also observed with CYP3A4 (Fig. 4); however, indications of differences were found in the regioselectivity in metabolites from albendazole, amiodarone thioridazine, mesoridazine, danazol, and astemizole after incubation with the two enzymes. Evidence showed that some metabolites were produced exclusively by CYP2J2. (Lee and Murray, 2010). Further investigation by Kaspera et al. (2014) showed the significant contribution of CYP2J2 to ritonavir metabolism in the liver, with a unique metabolism profile compared with CYP3A4/5. CYP2J2 produced specific metabolites from oxidation of the thiazole rings on different sides of the molecule. This study found that CYP2J2 had a greater affinity for ritonavir $\left(K_{\mathrm{m}} 0.016 \mu \mathrm{M}\right)$ compared with CYP3A4 $\left(K_{\mathrm{m}} 0.068 \mu \mathrm{M}\right)$ and CYP3A5 $\left(K_{\mathrm{m}} 0.047 \mu \mathrm{M}\right)$ in liver microsomes (Kaspera et al., 2014). In addition, CYP2J2 and CYP2C19 were the major enzymes responsible for the metabolism of albendazole and fenbendazole in human liver microsomes. Both these drugs can be transformed to their sulfoxide and hydroxyl metabolites ( $\mathrm{Wu}$ et al., 2013). CYP3A4 and flavin-containing monooxygenase are thought to be major enzymes in producing sulfoxide metabolites (Virkel et al., 2004); however, Wu et al., (2013) demonstrated CYP2J2 to be the primary enzyme mediating albendazole hydroxylation. CYP2C19 and CYP2E1 also contributed to this hydroxylation but to a lesser extent. (Wu et al., 2013). The consequences of the formation of these specific metabolites by CYP2J2 has yet to be fully determined.

Several CYP2J2 substrates are known to have pharmacologic effects in the heart and may be metabolized in this tissue (Evangelista et al., 2013). Applying this logic, CYP2J2 may be able to regulate the local concentrations of these compounds and therefore modulate cardiotoxicity. Studies in heart microsomes incubated with verapamil led to the formation of nine P450 metabolites. As verapamil is an L-type calcium channel blocker, which is commonly prescribed for heart conditions such as angina and arrhythmias, CYP2J2 may be able to regulate functional activity of the drug (Michaud et al., 2010). Furthermore, in isolated rat heart hydroxylation of the $\mathrm{H}_{1}$ receptor antagonist, ebastine to hydroxyebastine and carebastine was detected and compared with human liver microsomes and showed a similar metabolism profile; however, as there was no comparison with metabolism in the human heart, it is difficult to ascertain comparative activity between CYP2J2

TABLE 4

Range of substrates for CYP2J2 and the metabolic pathways by which they are formed

Substrates include both endogenous compounds and exogenous drugs and the main metabolic pathways are hydroxylation and epoxygenation.

\begin{tabular}{|c|c|c|c|}
\hline Substrate & Metabolic Pathway & $K_{\mathrm{m}}(\mu \mathrm{M})^{a}$ & $\mathrm{~V}_{\max } /$ Turnover No. $(\mathrm{nmol} / \mathrm{min} \text { per } \mathrm{nmol})^{a}$ \\
\hline \multicolumn{4}{|l|}{ Endogenous } \\
\hline Arachidonic acid & Epoxygenation & & 0.065 \\
\hline Linoleic acid & Epoxygenation & & 0.105 \\
\hline Docosahexaenoic acid & $\begin{array}{l}\text { Epoxygenation (major) } \omega-1 / \omega \\
\text { hydroxylation (minor) }\end{array}$ & & $0.228 \pm 0.008$ \\
\hline Eicosapentaenoic acid & $\begin{array}{l}\text { Epoxygenation (major) } \omega-1 / \omega \\
\text { hydroxylation (minor) }\end{array}$ & & $0.943 \pm 0.017$ \\
\hline Vitamin D3 & 25-Hydroxylation & $7.7 \pm 1.2$ & $0.087 \pm 0.013$ \\
\hline Vitamin D2 & 25-Hydroxylation & $2.0 \pm 0.3$ & $0.16 \pm 0.03$ \\
\hline $1 \alpha(\mathrm{OH}) \mathrm{D} 3$ & 25-Hydroxylation & $4.4 \pm 0.7$ & 2.2 \\
\hline \multicolumn{4}{|l|}{ Drugs } \\
\hline Albendazole & $\omega$-Hydroxylation sulfoxidation & & \\
\hline Amiodarone & 3-Hydroxylation 4-hydroxylation & 5 & 4.6 \\
\hline Apixaban & O-demethylation & & $0.27 \pm 0.06$ \\
\hline Astemizole $^{\mathrm{a}}$ & O-demethylation & 0.65 & 1.129 \\
\hline Benzphetamine & N-demethylation & & 0.08 \\
\hline Bufuralol & & & 0.17 \\
\hline Cyclosporine A & Hydroxylation & & \\
\hline Danazol & Hydroxylation & & \\
\hline Ebastin $^{a}$ & Hydroxylation & $1.3 / 18.3$ & $40.6 / 8.2$ \\
\hline Eperisone & $\omega$ - Hydroxylation $\omega$-1 hydroxylation & & 0.0266 \\
\hline Hydroxyebastine & Carboxylation & 0.75 & 9.86 \\
\hline Terfenadine & Hydroxylation & 0.4 & 20 \\
\hline Thioridazine & Sulfoxidation & & \\
\hline Vorapaxar & Hydroxylation & & 0.0306 \\
\hline
\end{tabular}

${ }^{a}$ Metabolic pathway used solely by CYP2J2

${ }^{b}$ Some $K_{\mathrm{m}}$ and $V_{\max }$ values remain unknown. 


\section{Products of CYP3A4}

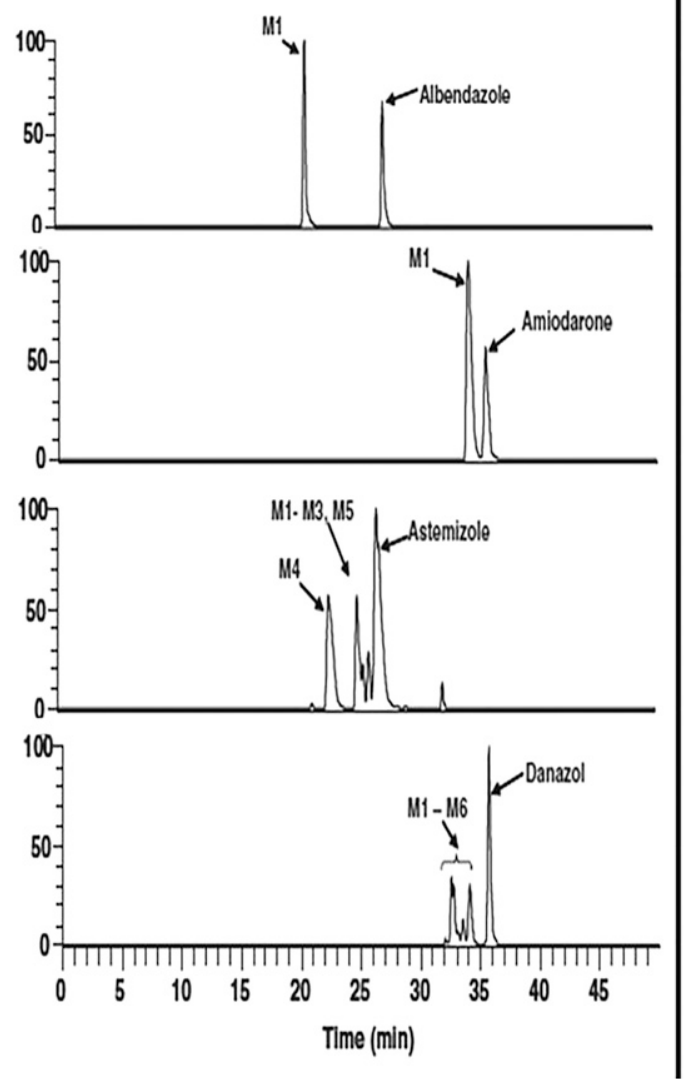

Products of CYP2J2

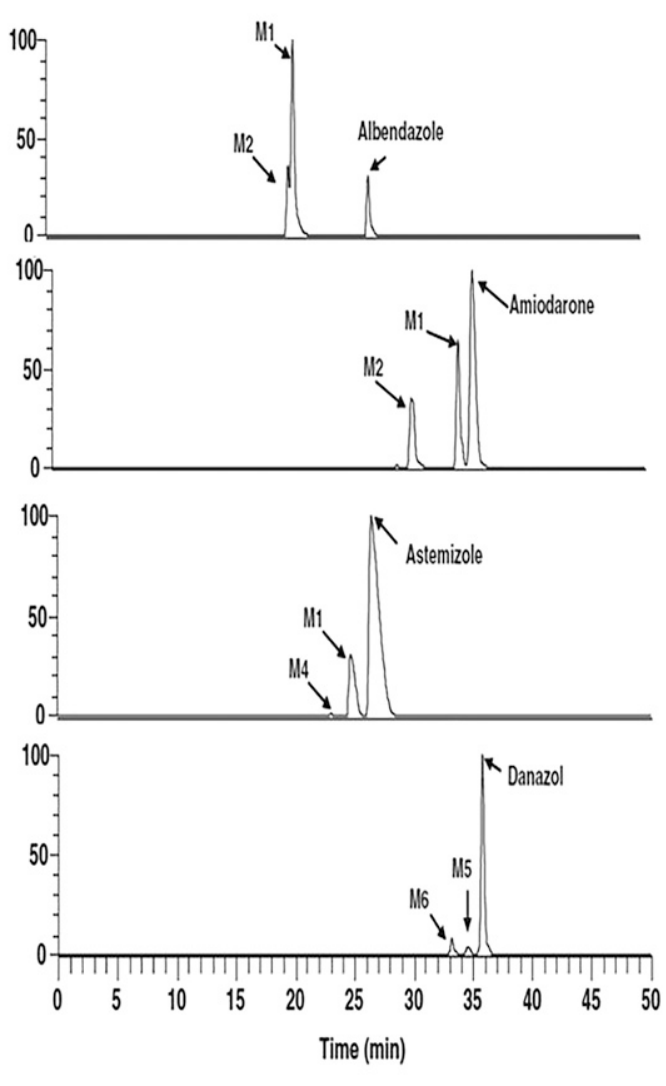

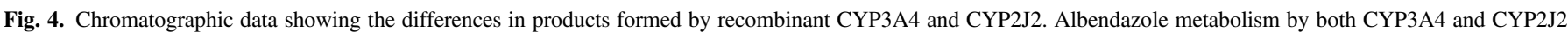

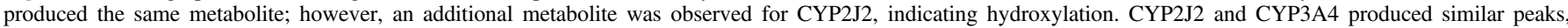

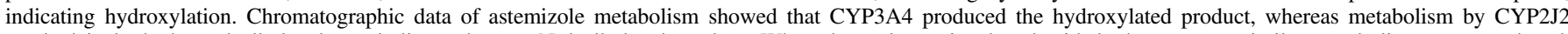

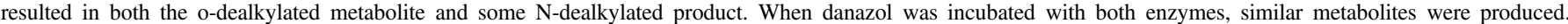
(Reproduced, with permission, from Lee et al., 2010).

and CYP2J3. It is also unclear whether other P450 enzymes could be responsible, in part, for ebastine metabolism (Kang et al., 2011). Overall, the metabolic activity of CYP2J2 in the liver and its ability to metabolize a wide array of drugs, coupled with its high expression in the heart, warrant further studies to clarify the significance of cardiac CYP2J2 in drug metabolism in physiologic relevant systems.

\section{Modulation of CYP2J2 Activity by Drugs}

Evangelista et al. (2013) investigated the role of different drugs in the induction and inhibition of CYP2J2 in adult primary human cardiomyocytes. A major limitation of this research is that the cells used in this study can divide and are morphologically and functionally different compared with freshly isolated cells. CYP2J2 activity was measured via terfenadine hydroxylation at two different inhibitor concentrations. The most potent inhibitor of CYP2J2 tested was danazol, which reduced activity by $\sim 95 \%$; other less potent inhibitors included ketoconazole and astemizole (Evangelista et al., 2013). In addition to the inhibitors of CYP2J2 recognized in this review, other drugs are reviewed elsewhere (Lafite et al., 2007; VanAlstine and Hough, 2011).

A more recent study highlighted the reversible mixed-mode inhibition of recombinant CYP2J2 by dronedarone $\left(K_{\mathrm{i}}=0.034 \mu \mathrm{M}\right)$, amiodarone $\left(K_{\mathrm{i}}=4.8 \mu \mathrm{M}\right)$, and their active metabolites, $N$-desbutyldronedarone (NDBD) $\left(K_{\mathrm{i}}=0.55 \mu \mathrm{M}\right)$ and $N$-desethylamiodarone (NDEA) $\left(K_{\mathrm{i}}=\right.$ $7.4 \mu \mathrm{M})$ and further irreversible inhibition by dronedarone and NDBD
(Karkhanis et al., 2016). Both these drugs are multi-ion channel blockers designed to reduce cardiac arrhythmias but paradoxically are potentially also cardiotoxic, resulting in bradycardia, hypotension, congestive heart failure, and ventricular tachycardia (Dixon et al., 2013). Dronedarone has been demonstrated to cause a reduction in a recurrent atrial fibrillation in patients compared with amiodarone (Piccini et al., 2009) but can lead to QT prolongation and subsequently TdP in some instances (Heijman et al., 2013). As both amiodarone and dronedarone are substrates for CYP2J2, the interaction between these drugs and CYP2J2 may modulate cardiac side effects and drug-drug interactions, leading to further toxicity. Dronedarone, amiodarone, and their respective metabolites have been shown to inhibit CYP2J2-mediated AA metabolism and production of EETs, NDBD being the most potent (Karkhanis et al., 2017). Because of the protective role of CYP2J2 in cardiac function, it is feasible that the inhibition of CYP2J2 may block epoxygenase activity and reduce protective EETs, although our understanding of the interplay between drug metabolism and EET formation is rudimentary. In addition, it is possible that modulation of CYP2J2 activity may lead to altered levels of toxic parent compound or toxic metabolite and changes in the toxicity profile. These concepts are worthy of further study and analysis.

\section{Potential Role of EETs in Mitigating Drug-Induced Cardiotoxicity}

The mechanisms by which compounds cause cardiotoxicity resulting in changes in ECG waveforms/intervals, hemodynamics, or cardiac 
pathology are diverse and compound-specific. Each of these outcomes can be further defined both in terms of the physiologic and pathologic state and the molecular mechanism and or pathways by which perturbations arise. Currently, the level of molecular understanding varies considerably, depending on the physiologic or pathologic perturbation. For example, the ion channels behind the cardiac action potential, and thus changes in the ECG, are well defined. In contrast, multiple mechanisms are proposed for changes in cardiac pathology. For example, the anticancer tyrosine kinase inhibitor sunitinib causes oxidative stress (Aparicio-Gallego et al., 2011) and cardiac hypertrophy (Maayah et al., 2014); whether these perturbations are linked and whether upstream unidentified mechanisms exist remain to be determined; however, with this diversity of molecular mechanisms responsible for cardiotoxicity, the role of EETs in cardioprotection is just as diverse (Table 5). In an animal model of isoproterenol-induced cardiac hypertrophy, the use of sEH inhibitors increased the levels of EETs and decreased the induction of ANP and BNP and EPHX2 mRNA (Althurwi et al., 2013). Furthermore, increased circulating EETs reduced oxidative stress and increased expression of antioxidant enzymes (Wang et al., 2014). Therefore, some evidence suggests that protection against sunitinib (and other drug) toxicity may be achieved by an upregulation of these epoxygenases with resultant promotion of EET formation.

Other cardiotoxic drugs, such as the antiarrhythmic drug amiodarone, alter apoptotic pathways, increasing caspase 3 activity and leading to an increase in apoptosis and cell death in h9c2 cells (Isomoto et al., 2006). The addition of exogenous EETs in vitro boosts activity of the prosurvival enzyme PI3K and inhibits proapoptotic pathways in primary cardiomyocytes derived from a rat heart hypoxia/reperfusion model (Dhanasekaran et al., 2008).

Cardiotoxic drugs also impact hemodynamics within the cardiovascular system. An example of detrimental effects of drugs on blood pressure is the CYP2J2 substrate 5-fluorouracil, which has been shown to be vasoconstrictive through the inhibition of nitric oxide synthase, leading to coronary spasms, and via protein kinase $\mathrm{C}$, leading to vasoconstriction (Alter et al., 2006). Inhibition of $\mathrm{sEH}$ increased EETs and dilated human coronary arterioles through $\mathrm{BK}_{\mathrm{ca}}$ channels, and 11,12-EET also caused relaxation of rat coronary arteries and renal and cerebral arteries of rats and rabbits. (Campbell et al., 1996; Fisslthaler et al., 1999, Imig et al., 2001; Larsen et al., 2006; Dimitropoulou et al., 2007). Taken together, EETs act on several pathways involved in cardiotoxicity, and there is circumstantial yet plausible evidence to suggest a protective impact of CYP2J2 via EET synthesis in the heart during cardiotoxicity.

\section{Role of CYP2J2 in DOX-Induced Cardiotoxicity}

The strongest case for a role of CYP2J2 in protection against cardiotoxicity has been presented for DOX. DOX is an anthracycline used for the treatment of solid tumors and hematologic carcinomas, which has been shown to modulate CYP2J2 production of EETs. Despite its anticancer action, the clinical value of this drug is reduced owing to acute and chronic, cumulative, and irreversible dose-dependent cardiotoxicity (Belham et al., 2007). Cardiovascular effects include acute cardiomyopathy, chronic heart failure, ventricular dysfunction, and arrhythmias (Yeh et al., 2004). Currently, it is unclear whether the mechanism of cardiotoxicity is the same when occurring acutely (within days) or chronically (years) after treatment (Takemura and Fujiwara, 2007).

Preclinically, both acute and chronic DOX administration have been associated with changes in EET formation (Zordoky et al., 2010; Alsaad et al., 2012). In rats, acute DOX treatment altered the mRNA expression of P450 and sEH enzymes in kidney and liver, leading to decreases in 5,6-, 8,9-, 11,12-, and 14,15-EET (Zordoky et al., 2010). Ichikawa et al. (2014) found that acute DOX-induced cardiotoxicity was associated with generation of ROS, cellular iron accumulation, and disruption of the mitochondria, which in turn initiated apoptotic pathways in isolated neonatal rat cardiomyocytes (Ichikawa et al., 2014). Previously, EETs have been shown to attenuate production of ROS and mitochondrial dysfunction in carcinoma cells treated with arsenic trioxide (Liu et al., 2011), and an interesting and potentially important study suggested that CYP2J2 mRNA expression increased in adult human ventricular myocytes in culture in response to both external oxidants and addition of DOX; the latter, among other effects, stimulates intracellular oxidant production. Moreover, cell survival decreased with oxidant exposure when CYP2J2 was inhibited either using danazol or by siRNA for CYP2J2. Not surprisingly, this ROS toxicity was mitigated with the addition of exogenous EETs. Although the report is intriguing and plausible, there are limitations to be highlighted. The use of millimolar concentrations of pyruvate as the only antioxidant trialed limits mechanistic interpretation, as does the use of danazol as a CYP2J2 inhibitor; however, in support of CYP2J2-derived EETs as protective agents, knockdown of CYP2J2 mRNA also negatively affected cell survival after DOX, yet levels of CYP2J2 protein were not addressed. The relatively nonspecific measurement of intracellular oxidant formation resulting from DOX treatment of cells also limits interpretation of the mechanism of molecular signaling. Nevertheless, this mechanism may have implications for other cardiotoxic compounds acting, in part, via oxidant formation in cells of the cardiovascular system. If the mechanism is proven to be mediated by increased oxidants in cells, then protection from these agents could also be afforded by changes in CYP2J2 gene expression and the resultant increased EET formation.

Alsaad et al. (2012) studied the effects of chronic DOX cardiotoxicity in the heart on the mRNA expression of proteins involved in the formation of AA metabolites, as well as levels of these metabolites via liquid chromatography/mass spectroscopy in rats. Animals were treated with multiple intraperitoneal injections over 14 days, followed by a 14-day recovery period, emulating the clinical administration (Alsaad et al., 2012). Chronic DOX treatment in vivo caused no change in mRNA expression of the rat analog of CYP2J2, CYP2J3; however, it increased mRNA expression of other P450 enzymes, including CYP4A3, CYP4F1, and CYP4F5, known to produce the alternative AA metabolite 20-HETE, resulting in increased levels of 20-HETE compared with an untreated control group (Alsaad et al., 2012). These investigators also observed a rise in the mRNA expression of the EPHX2 (sEH) gene in the heart in DOX-treated rats, accompanied by decreased EET levels and an increase in the levels of inactive DHETs. Furthermore, treatment of H9c2 cells, a rat cardiac cell line, with a sEH inhibitor (t-AUCB), in combination with DOX, reduced both ANP and BNP release (markers of cardiac hypertrophy), suggesting a cardioprotective effect of $\mathrm{sEH}$ inhibition. Additionally, DOX upregulates levels of many P450 enzymes in this cell model, including 2J3 and 2E1 (Zordoky and El-Kadi, 2008b). Given the biologic protective activity of EETs, particularly 11,12-EET and 14,15-EET against cardiovascular disease (Sudhahar et al., 2010), it is hypothesized that EETs may provide protection against cardiotoxicity induced by a whole spectrum of xenobiotics in vivo.

Discrepancies in mRNA expression between acute and chronic DOX administration have been documented (Zordoky et al., 2010; Alsaad et al., 2012), highlighting the caution required when interpreting studies comparing acute versus chronic DOX administration. Furthermore, the treatment period used by Alsaad and colleagues may not be sufficient to induce many of the characteristic features of chronic DOX cardiotoxicity. A detailed assessment by Cove-Smith et al. (2014) of both cardiac 


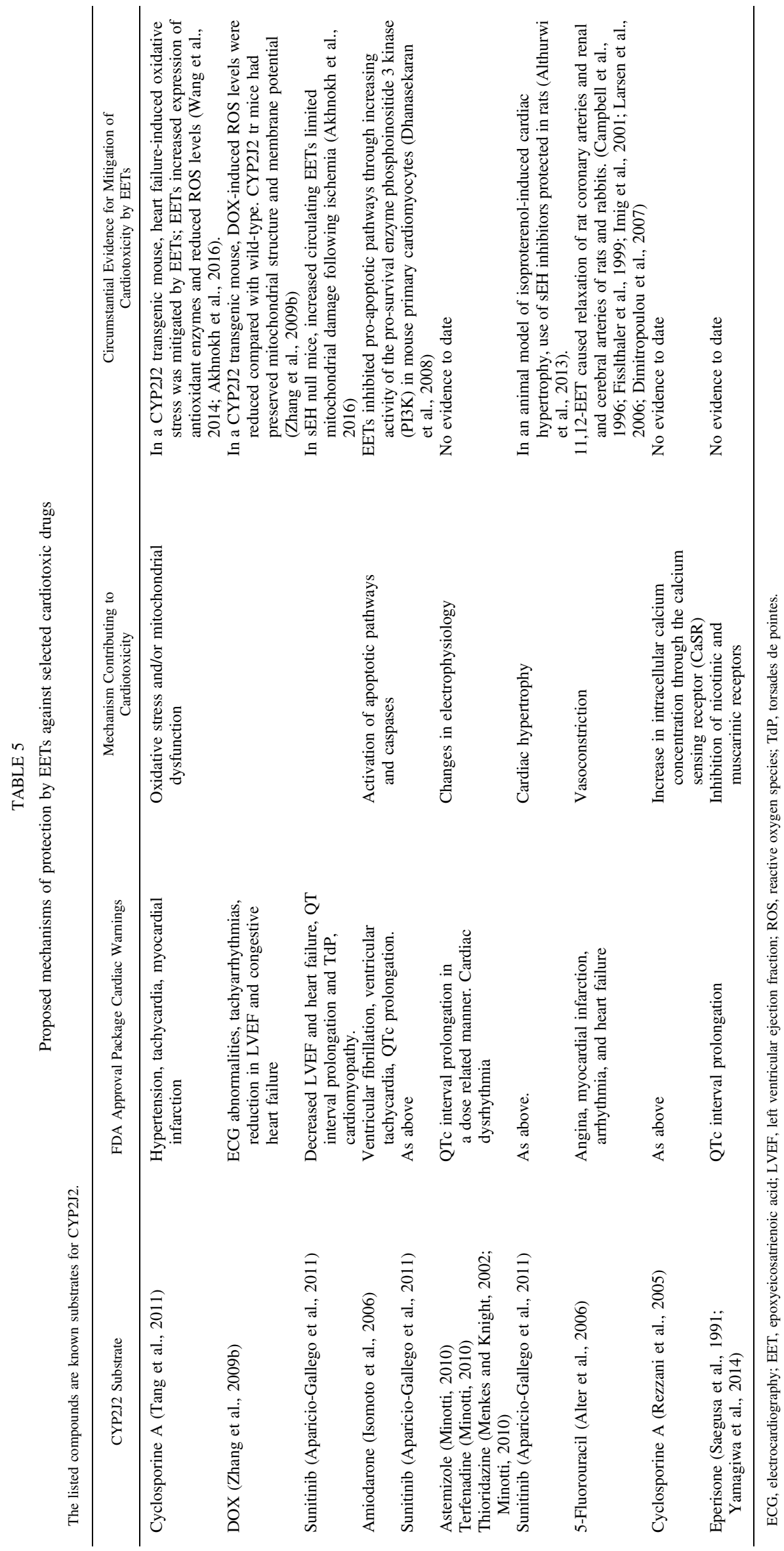


morphology and function in rats for 8 weeks after $1.25 \mathrm{mg} / \mathrm{kg}$ DOX demonstrated changes in cardiac function, in particular, cardiac output, stroke volume, and ejection fraction from day 15 . Gross morphologic changes and biomarkers associated with cardiomyocyte degeneration occurred much later (Cove-Smith et al., 2014). Consequently, the changes observed after 2 weeks of DOX treatment are unlikely to be a true indication of the protective role of EETs during DOX cardiotoxicity, and therefore the study length would need to be extended to determine this role definitively; however, it is plausible to suggest that epoxygenase enzymes are involved in the cellular development of DOX-induced cardiotoxicity.

Using transgenic mice with cardiomyocyte-specific overexpression of human CYP2J2, Zhang et al. (2009b) identified the possible beneficial effects of EETs in the protection against DOX-induced cardiotoxicity. Elevations in serum LDH and $\mathrm{CK}$ and activation of cardiac caspase 3 and catalase caused by acute treatment with $\operatorname{DOX}(0,5$ and $15 \mathrm{mg} \mathrm{DOX} / \mathrm{kg}$ daily i.p. for 3 days followed by 24-hour recovery) were mitigated in mice overexpressing CYP2J2, suggesting protection against DOX-induced myocardial damage. Some of these markers are not specific to the heart, however, and this may affect the interpretation of these findings. After chronic treatment with DOX $(0,1.5,3 \mathrm{mg} / \mathrm{kg}$ biweekly for 5 weeks followed by a 2-week recovery), the CYP2J2 transgenic mice showed a lower heart weight-to-body ratio, reduced cardiac ankyrin repeat protein (CARP), and expression ratio of $\beta \mathrm{MHC}: \alpha \mathrm{MHC}$, and no change in LVDP compared with wildtype mice. This finding indicates that cardiac structure and contractile function that may have been mediated by protective EETs (Zhang et al., 2009 b) were preserved. Although cardiac ankyrin repeat protein is a specific biomarker of cardiac hypertrophy, it may not be a good biomarker of early cardiac remodeling. In fact, many of the serologic, pathologic, and functional biomarkers of early cardiac damage during cardiotoxicity were not reported. For example, cardiac troponin, which is known to be the gold standard in investigating cardiac damage preclinically and clinically, was not measured (Cove-Smith et al., 2014).

Studies have found that CYP2J2 is capable of metabolizing DOX (Zhang et al., 2009b); however, as this was a CYP2J2 transgenic model and not a null model, other P450 enzymes may also be responsible for the increased metabolism of DOX. Furthermore, increased expression and activity of reductase in the transgenic mouse hearts may also lead to an increase in activity of many other P450 enzymes. It is known that the major metabolite of DOX, doxorubicinol (DOXol), contributes to toxicity in the myocardium; however, other evidence suggests other metabolites of DOX, including DOX deoxyaglycone and DOXol hydroxyaglycone, may also contribute to the cardiotoxicity (Licata et al., 2000). In addition, P450 reductase can metabolize DOX to 7-deoxydoxyrubicin aglycone, which has been shown to inhibit AA metabolism, reducing the production of EETs and altering the regiosomers of EETs produced (Arnold et al., 2017). Therefore, increased metabolism through CYP2J2 may have a conflicting effect on the heart, elevating levels of toxic metabolites for certain drugs but increasing protection through EETs. Other P450 enzymes belonging to the murine CYP2J family, including CYP2J8, 2J11, 2J12, and 2J13, also have epoxidase activity toward AA, which may confound results, especially as expression levels of these enzymes were not measured in the CYP2J2 transgenic mice (Graves et al., 2013). In rats, only CYP2J3 has been demonstrated to possess expoxygenase activity, and so protective effects by EETs may be less apparent. In addition, the use of transgenic models where there is a genetic alteration, leading to differences in protein expression and hence activity, may not directly model pharmacologic activation of CYP2J2 in the wild-type mouse (Knight and Shokat, 2007).

Taken together, the limited number of studies on DOX toxicity suggests that CYP2J2 expression and EET production have profound cardioprotective effects, modulating DOX cardiotoxicity through their influence on molecular pathways involved in apoptosis, ROS generation, hypertrophy, and cardiac remodeling, leading to an overall conservation of structure and function. It may be hypothesized that the cardiac potential of other drugs might be affected by CYP2J2 metabolism and/or EET formation. The effects of EETs on DOX raises the possibility that the CYP2J2/EET pathway may also modulate the cardiotoxicity of other drugs, working through different mechanisms (Table 5).

\section{Conclusions}

CYP2J2 is an AA and drug-metabolizing enzyme highly expressed in the human heart; however, the role of CYP2J2 in drug metabolism in the heart has not been well defined. Nevertheless, there is increasing awareness that many current drugs are substrates for CYP2J2. Substantial data suggest that CYP2J2, along with CYP3A4, plays a significant part in the metabolism of drugs known to cause cardiotoxicity. Therefore, changes in the expression or activity of this enzyme may alter drug concentrations in the body, leading to either an ineffective drug response or increased levels of metabolites, thereby leading to potential cardiotoxicity. Known P450 inducers do not modulate CYP2J2 levels, but some compounds have been recognized to induce the expression and activity of CYP2J 2 in adult human cardiomyocytes. In addition, several SNPs in the human CYP2J2 gene are associated with altered in vitro activity of the CYP2J2 enzyme, which may lead to changes in EET formation and drug metabolism, potentially altering cardiotoxicity in some individuals. In addition to its role in drug metabolism, CYP2J2-derived EETs have also been shown to have a protective effect, although this has only really been reported for DOX-induced cardiotoxicity. Given that our understanding of the role of CYP2J2 and EET formation is based largely on the data from this single drug and the importance of cardiotoxicity to drug development and application in humans, understanding more fully the role and possible protection by CYP2J2 in the heart is worthy of further study.

\section{Authorship Contributions}

Wrote or contributed to the writing of the manuscript: Solanki, Pointon, Jones, Herbert.

\section{References}

Akhnokh MK, Yang FH, Samokhvalov V, Jamieson KL, Cho WJ, Wagg C, Takawale A, Wang X, Lopaschuk GD, Hammock BD, et al. (2016) Inhibition of soluble epoxide hydrolase limits mitochondrial damage and preserves function following ischemic injury. Front Pharmacol 7: 133.

Alsaad AM, Zordoky BN, El-Sherbeni AA, and El-Kadi AO (2012) Chronic doxorubicin cardiotoxicity modulates cardiac cytochrome P450-mediated arachidonic acid metabolism in rats. Drug Metab Dispos 40:2126-2135.

Alsaad AM, Zordoky BN, Tse MM, and El-Kadi AO (2013) Role of cytochrome P450-mediated arachidonic acid metabolites in the pathogenesis of cardiac hypertrophy. Drug Metab Rev 45: $173-195$

Alter P, Herzum M, Soufi M, Schaefer J, and Maisch B (2006) Cardiotoxicity of 5-fluorouracil. Cardiovasc Hematol Agents Med Chem 4:1-5.

Althurwi HN, Tse MM, Abdelhamid G, Zordoky BN, Hammock BD, and El-Kadi AO (2013) Soluble epoxide hydrolase inhibitor, TUPS, protects against isoprenaline-induced cardiac hypertrophy. Br J Pharmacol 168:1794-1807.

Anandan SK, Webb HK, Chen D, Wang YX, Aavula BR, Cases S, Cheng Y, Do ZN, Mehra U, Tran V, et al. (2011) 1-(1-acetyl-piperidin-4-yl)-3-adamantan-1-yl-urea (AR9281) as a potent, selective, and orally available soluble epoxide hydrolase inhibitor with efficacy in rodent models of hypertension and dysglycemia. Bioorg Med Chem Lett 21:983-988.

Aparicio-Gallego G, Blanco M, Figueroa A, García-Campelo R, Valladares-Ayerbes M, Grande-Pulido E, and Antón-Aparicio L (2011) New insights into molecular mechanisms of sunitinib-associated side effects. Molecular cancer therapeutics 10(12):2215-2223.

Arnold WR, Baylon JL, Tajkhorshid E, and Das A (2017) Arachidonic acid metabolism by human cardiovascular CYP2J2 is modulated by doxorubicin. Biochemistry 56:6700-6712.

Barau C, Ghaleh B, Berdeaux A, and Morin D (2015) Cytochrome P450 and myocardial ischemia: potential pharmacological implication for cardioprotection. Fundam Clin Pharmacol 29:1-9.

Belham M, Kruger A, Mepham S, Faganello G, and Pritchard C (2007) Monitoring left ventricular function in adults receiving anthracycline-containing chemotherapy. Eur J Heart Fail 9: 409-414.

Berlin DS, Sangkuhl K, Klein TE, and Altman RB (2011) PharmGKB summary: cytochrome P450, family 2, subfamily J, polypeptide 2: CYP2J2. Pharmacogenet Genomics 21:308-311. Bernstrom K, Kayganich K, Murphy RC, and Fitzpatrick FA (1992) Incorporation and distribution of epoxyeicosatrienoic acids into cellular phospholipids. J Biol Chem 267:3686-3690. 
Bertrand-Thiebault C, Ferrari L, Boutherin-Falson O, Kockx M, Desquand-Billiald S, Fichelle JM, Nottin R, Renaud JF, Batt AM, and Visvikis S (2004) Cytochromes P450 are differently expressed in normal and varicose human saphenous veins: linkage with varicosis. Clin Exp Pharmacol Physiol 31:295-301.

Brutsaert DL (2003) Cardiac endothelial-myocardial signaling: its role in cardiac growth, contractile performance, and rhythmicity. Physiol Rev 83:59-115.

Bylund J, Bylund M, and Oliw EH (2001) cDna cloning and expression of CYP4F12, a nove human cytochrome P450. Biochem Biophys Res Commun 280:892-897.

Bystrom J, Wray JA, Sugden MC, Holness MJ, Swales KE, Warner TD, Edin ML, Zeldin DC, Gilroy DW, and Bishop-Bailey D (2011) Endogenous epoxygenases are modulators of monocyte/macrophage activity. PLoS One 6:e26591.

Campbell WB and Fleming I (2010) Epoxyeicosatrienoic acids and endothelium-dependent responses. Pflugers Arch 459:881-895.

Campbell WB, Gebremedhin D, Pratt PF, and Harder DR (1996) Identification of epoxyeicosatrienoic acids as endothelium-derived hyperpolarizing factors. Circ Res 78:415-423.

Chatterjee K, Zhang J, Honbo N, and Karliner JS (2010) Doxorubicin cardiomyopathy. Cardiology 115: $155-162$.

Chaudhary KR, Batchu SN, and Seubert JM (2009) Cytochrome P450 enzymes and the heart. IUBMB Life 61:954-960.

Cove-Smith L, Woodhouse N, Hargreaves A, Kirk J, Smith S, Price SA, Galvin M, Betts CJ, Brocklehurst S, Backen A, et al. (2014) An integrated characterization of serological, pathological, and functional events in doxorubicin-induced cardiotoxicity. Toxicol Sci 140:3-15.

Dai M, Wu L, He Z, Zhang S, Chen C, Xu X, Wang P, Gruzdev A, Zeldin DC, and Wang DW (2015) Epoxyeicosatrienoic acids regulate macrophage polarization and prevent LPS-induced cardiac dysfunction. J Cell Physiol 230:2108-2119.

Deb A and Ubil E (2014) Cardiac fibroblast in development and wound healing. J Mol Cell Cardio 70:47-55.

Delozier TC, Kissling GE, Coulter SJ, Dai D, Foley JF, Bradbury JA, Murphy E, Steenbergen C, Zeldin DC, and Goldstein JA (2007) Detection of human CYP2C8, CYP2C9, and CYP2J2 in cardiovascular tissues. Drug Metab Dispos 35:682-688.

Dhanasekaran A, Gruenloh SK, Buonaccorsi JN, Zhang R, Gross GJ, Falck JR, Patel PK, Jacobs ER, and Medhora M (2008) Multiple antiapoptotic targets of the PI3K/Akt survival pathway are activated by epoxyeicosatrienoic acids to protect cardiomyocytes from hypoxia/anoxia. Am J Physiol Heart Circ Physiol 294:H724-H735.

Dimitropoulou C, West L, Field MB, White RE, Reddy LM, Falck JR, and Imig JD (2007) Protein phosphatase 2A and $\mathrm{Ca} 2+$-activated $\mathrm{K}+$ channels contribute to 11,12-epoxyeicosatrienoic acid analog mediated mesenteric arterial relaxation. Prostaglandins Other Lipid Mediat 83:50-61.

Dixon K, Thanavaro J, Thais A, and Lavin MA (2013) Amiodarone surveillance in primary care. I Nurse Pract 9:46-54.

Dutheil F, Dauchy S, Diry M, Sazdovitch V, Cloarec O, Mellottée L, Bièche I, Ingelman-Sundberg M, Flinois JP, de Waziers I, et al. (2009) Xenobiotic-metabolizing enzymes and transporters in the normal human brain: regional and cellular mapping as a basis for putative roles in cerebral function. Drug Metab Dispos 37:1528-1538.

Edin ML, Wang Z, Bradbury JA, Graves JP, Lih FB, DeGraff LM, Foley JF, Torphy R, Ronnekleiv OK, Tomer KB, et al. (2011) Endothelial expression of human cytochrome P450 epoxygenase CYP2C8 increases susceptibility to ischemia-reperfusion injury in isolated mouse heart. FASEB $J$ 25:3436-3447.

Enayetallah AE, French RA, Thibodeau MS, and Grant DF (2004) Distribution of soluble epoxide hydrolase and of cytochrome P450 2C8, 2C9, and $2 \mathrm{~J} 2$ in human tissues. J Histochem Cytochem 52:447-454.

Evangelista EA, Kaspera R, Mokadam NA, Jones JP, III, and Totah RA (2013) Activity, inhibition, and induction of cytochrome P450 2J2 in adult human primary cardiomyocytes. Drug Metab Dispos 41:2087-2094.

Fava C, Montagnana M, Almgren P, Hedblad B, Engström G, Berglund G, Minuz P, and Melander $\mathrm{O}$ (2010) The common functional polymorphism $-50 \mathrm{G}>\mathrm{T}$ of the CYP2J2 gene is not associated with ischemic coronary and cerebrovascular events in an urban-based sample of Swedes. J Hypertens 28:294-299.

Feenstra J, Grobbee DE, Remme WJ, and Stricker BHC (1999) Drug-induced heart failure. J Am Coll Cardiol 33:1152-1162.

Fisslthaler B, Popp R, Kiss L, Potente M, Harder DR, Fleming I, and Busse R (1999) Cytochrome P450 2C is an EDHF synthase in coronary arteries. Nature 401:493-497.

Fleming I (2001) Cytochrome p450 and vascular homeostasis. Circ Res 89:753-762.

Gaedigk A, Baker DW, Totah RA, Gaedigk R, Pearce RE, Vyhlidal CA, Zeldin DC, and Leeder JS (2006) Variability of CYP2J2 expression in human fetal tissues. J Pharmacol Exp Ther 319 $523-532$.

Gonzalez FJ, Fang ZZ, and Ma X (2015) Transgenic mice and metabolomics for study of hepatic xenobiotic metabolism and toxicity. Expert Opin Drug Metab Toxicol 11:869-881.

Graves JP, Edin ML, Bradbury JA, Gruzdev A, Cheng J, Lih FB, Masinde TA, Qu W, Clayton NP, Morrison JP, et al. (2013) Characterization of four new mouse cytochrome P450 enzymes of the CYP2J subfamily. Drug Metab Dispos 41:763-773.

Harmon SD, Fang X, Kaduce TL, Hu S, Raj Gopal V, Falck JR, and Spector AA (2006) Oxygenation of $\omega-3$ fatty acids by human cytochrome P450 4F3B: effect on 20-hydroxyeicosatetraenoic acid production. Prostaglandins Leukot Essent Fatty Acids 75:169-177.

Heijman J, Heusch G, and Dobrev D (2013) Pleiotropic effects of antiarrhythmic agents: dronedarone in the treatment of atrial fibrillation. Clin Med Insights Cardiol 7:127-140.

Hoffmann MM, Bugert P, Seelhorst U, Wellnitz B, Winkelmann BR, Boehm BO, and März W (2007) The $-50 \mathrm{G}>\mathrm{T}$ polymorphism in the promoter of the CYP2J2 gene in coronary hear disease: the Ludwigshafen Risk and Cardiovascular Health study. Clin Chem 53:539-540.

Hwang SH, Wecksler AT, Zhang G, Morisseau C, Nguyen LV, Fu SH, and Hammock BD (2013) Synthesis and biological evaluation of sorafenib- and regorafenib-like sEH inhibitors. Bioorg Med Chem Lett 23:3732-3737.

Ichikawa Y, Ghanefar M, Bayeva M, Wu R, Khechaduri A, Naga Prasad SV, Mutharasan RK, Naik TJ, and Ardehali H (2014) Cardiotoxicity of doxorubicin is mediated through mitochondrial iron accumulation. J Clin Invest 124:617-630.

Imig JD, Zhao X, Falck JR, Wei S, and Capdevila JH (2001) Enhanced renal microvascular reactivity to angiotensin II in hypertension is ameliorated by the sulfonimide analog of 11,12 epoxyeicosatrienoic acid. J Hypertens 19:983-992.

Isomoto S, Kawakami A, Arakaki T, Yamashita S, Yano K, and Ono K (2006) Effects of antiarrhythmic drugs on apoptotic pathways in H9c2 cardiac cells. J Pharmacol Sci 101: $318-324$.
Jenkins CM, Cedars A, and Gross RW (2009) Eicosanoid signalling pathways in the heart. Cardiovasc Res 82:240-249.

Jiang JG, Chen CL, Card JW, Yang S, Chen JX, Fu XN, Ning YG, Xiao X, Zeldin DC, and Wang DW (2005) Cytochrome P450 2J2 promotes the neoplastic phenotype of carcinoma cells and is up-regulated in human tumors. Cancer Res 65:4707-4715.

Jie Z, Hong K, Jianhong T, Biao C, Yongmei Z, and Jingchuan L (2010) Haplotype analysis of the CYP2J2 gene associated with myocardial infarction in a Chinese Han population. Cell Biochem Funct 28:435-439.

Kang W, Elitzer S, Noh K, Bednarek T, and Weiss M (2011) Myocardial pharmacokinetics of ebastine, a substrate for cytochrome P450 2J, in rat isolated heart. $\mathrm{Br} J$ Pharmacol 163 $1733-1739$.

Karkhanis A, Lam HY, Venkatesan G, Koh SK, Chai CLL, Zhou L, Hong Y, Kojodjojo P, and Chan ECY (2016) Multiple modes of inhibition of human cytochrome P450 2J2 by dronedarone, amiodarone and their active metabolites. Biochem Pharmacol 107:67-80.

Karkhanis A, Tram NDT, and Chan ECY (2017) Effects of dronedarone, amiodarone and their active metabolites on sequential metabolism of arachidonic acid to epoxyeicosatrienoic and dihydroxyeicosatrienoic acids. Biochem Pharmacol 146:188-198.

Kaspera R, Kirby BJ, Sahele T, Collier AC, Kharasch ED, Unadkat JD, and Totah RA (2014) Investigating the contribution of $\mathrm{CYP} 2 \mathrm{~J} 2$ to ritonavir metabolism in vitro and in vivo. Biochem Pharmacol 91:109-118.

Kimes BW and Brandt BL (1976) Properties of a clonal muscle cell line from rat heart. Exp Cell Res 98:367-381.

King LM, Ma J, Srettabunjong S, Graves J, Bradbury JA, Li L, Spiecker M, Liao JK, Mohrenweiser H, and Zeldin DC (2002) Cloning of CYP2J2 gene and identification of functional polymorphisms. Mol Pharmacol 61:840-852.

Knight ZA and Shokat KM (2007) Chemical genetics: where genetics and pharmacology meet Cell 128:425-430.

Lafite P, Dijols S, Zeldin DC, Dansette PM, and Mansuy D (2007) Selective, competitive and mechanism-based inhibitors of human cytochrome P450 2J2. Arch Biochem Biophys 464: $155-168$.

Larsen BT, Campbell WB, and Gutterman DD (2007) Beyond vasodilatation: non-vasomotor roles of epoxyeicosatrienoic acids in the cardiovascular system. Trends Pharmacol Sci $\mathbf{2 8}$ $32-38$.

Larsen BT, Miura H, Hatoum OA, Campbell WB, Hammock BD, Zeldin DC, Falck JR, and Gutterman DD (2006) Epoxyeicosatrienoic and dihydroxyeicosatrienoic acids dilate human coronary arterioles via BK(Ca) channels: implications for soluble epoxide hydrolase inhibition. Am J Physiol Heart Circ Physiol 290:H491-H499.

Laverty H, Benson C, Cartwright E, Cross M, Garland C, Hammond T, Holloway C, McMahon N, Milligan J, Park B, et al. (2011) How can we improve our understanding of cardiovascular safety liabilities to develop safer medicines? Br J Pharmacol 163:675-693.

Lazaar AL, Yang L, Boardley RL, Goyal NS, Robertson J, Baldwin SJ, Newby DE, Wilkinson IB, Tal-Singer R, and Mayer RJ (2016) Pharmacokinetics, pharmacodynamics and adverse event profile of GSK2256294, a novel soluble epoxide hydrolase inhibitor. Br J Clin Pharmacol 81: 971-979.

Lee AC and Murray M (2010) Up-regulation of human CYP2J2 in HepG2 cells by butylated hydroxyanisole is mediated by c-Jun and Nrf2. Mol Pharmacol 77:987-994.

Lee CA, Neul D, Clouser-Roche A, Dalvie D, Wester MR, Jiang Y, Jones JP, III, Freiwald S, Zientek M, and Totah RA (2010) Identification of novel substrates for human cytochrome P450 2J2. Drug Metab Dispos 38:347-356.

Lee SS, Jeong HE, Liu KH, Ryu JY, Moon T, Yoon CN, Oh SJ, Yun CH, and Shin JG (2005) Identification and functional characterization of novel CYP2J2 variants: G312R variant cause loss of enzyme catalytic activity. Pharmacogenet Genomics 15:105-113.

Licata S, Saponiero A, Mordente A, and Minotti G (2000) Doxorubicin metabolism and toxicity in human myocardium: role of cytoplasmic deglycosidation and carbonyl reduction. Chem Res Toxicol 13:414-420.

Liu JY, Park SH, Morisseau C, Hwang SH, Hammock BD, and Weiss RH (2009) Sorafenib has soluble epoxide hydrolase inhibitory activity, which contributes to its effect profile in vivo. $M o$ Cancer Ther 8:2193-2203.

Liu KH, Kim MG, Lee DJ, Yoon YJ, Kim MJ, Shon JH, Choi CS, Choi YK, Desta Z, and Shin JG (2006) Characterization of ebastine, hydroxyebastine, and carebastine metabolism by human liver microsomes and expressed cytochrome P450 enzymes: major roles for CYP2J2 and CYP3A. Drug Metab Dispos 34:1793-1797.

Liu L, Chen C, Gong W, Li Y, Edin ML, Zeldin DC, and Wang DW (2011) Epoxyeicosatrienoic acids attenuate reactive oxygen species level, mitochondrial dysfunction, caspase activation, and apoptosis in carcinoma cells treated with arsenic trioxide. J Pharmacol Exp Ther 339:451-463.

Liu W, Wang T, He X, Liu X, Wang B, Liu Y, Li Z, Tan R, Ding C, Wang H, et al. (2016) CYP2J2 overexpression increases EETs and protects against HFD-induced atherosclerosis in ApoE-/ mice. J Cardiovasc Pharmacol 67:491-502.

Lu HR, Hermans AN, and Gallacher DJ (2012) Does terfenadine-induced ventricular tachycardia/ fibrillation directly relate to its QT prolongation and Torsades de Pointes? Br J Pharmacol 166 1490-1502.

Maayah ZH, Ansari MA, El Gendy MA, Al-Arifi MN, and Korashy HM (2014) Development of cardiac hypertrophy by sunitinib in vivo and in vitro rat cardiomyocytes is influenced by the aryl hydrocarbon receptor signaling pathway. Arch Toxicol 88:725-738.

Matsumoto S, Hirama T, Matsubara T, Nagata K, and Yamazoe Y (2002) Involvement of CYP2J2 on the intestinal first-pass metabolism of antihistamine drug, astemizole. Drug Metab Dispos 30 $1240-1245$.

Matsumoto S and Yamazoe Y (2001) Involvement of multiple human cytochromes P450 in the liver microsomal metabolism of astemizole and a comparison with terfenadine. $\mathrm{Br} \mathrm{J} \mathrm{Clin}$ Pharmacol 51:133-142.

Menkes DB and Knight JC (2002) Cardiotoxicity and prescription of thioridazine in New Zealand. Aust N Z J Psychiatry 36:492-498.

Mercuro G, Cadeddu C, Piras A, Dessì M, Madeddu C, Deidda M, Serpe R, Massa E, and Mantovani G (2007) Early epirubicin-induced myocardial dysfunction revealed by serial tissue Doppler echocardiography: correlation with inflammatory and oxidative stress markers. Oncologist 12:1124-1133.

Michaels S and Wang MZ (2014) The revised human liver cytochrome P450 "Pie": absolute protein quantification of CYP4F and CYP3A enzymes using targeted quantitative proteomics. Drug Metab Dispos 42:1241-1251. 
Michaud V, Frappier M, Dumas MC, and Turgeon J (2010) Metabolic activity and mRNA levels of human cardiac CYP450s involved in drug metabolism. PLoS One 5:e15666.

Minotti G (2010) Cardiotoxicity of Non-Cardiovascular Drugs, John Wiley \& Sons, New York.

Miyata N, Seki T, Tanaka Y, Omura T, Taniguchi K, Doi M, Bandou K, Kametani S, Sato M, Okuyama S, et al. (2005) Beneficial effects of a new 20-hydroxyeicosatetraenoic acid synthesis inhibitor, TS-011 [N-(3-chloro-4-morpholin-4-yl) phenyl-N'-hydroxyimido formamide], on hemorrhagic and ischemic stroke. J Pharmacol Exp Ther 314:77-85.

Nelson DR (2009) The cytochrome p450 homepage. Hum Genomics 4:59-65.

Nelson DR, Zeldin DC, Hoffman SM, Maltais LJ, Wain HM, and Nebert DW (2004) Comparison of cytochrome P450 (CYP) genes from the mouse and human genomes, including nomenclature recommendations for genes, pseudogenes and alternative-splice variants. Pharmacogenetics 14:1-18.

Newman JW, Morisseau C, and Hammock BD (2005) Epoxide hydrolases: their roles and interactions with lipid metabolism. Prog Lipid Res 44:1-51.

Nishimuta H, Sato K, Mizuki Y, Yabuki M, and Komuro S (2011) Species differences in intestinal metabolic activities of cytochrome P450 isoforms between cynomolgus monkeys and humans. Drug Metab Pharmacokinet 26:300-306.

Node K, Huo Y, Ruan X, Yang B, Spiecker M, Ley K, Zeldin DC, and Liao JK (1999) Antiinflammatory properties of cytochrome P450 epoxygenase-derived eicosanoids. Science $\mathbf{2 8 5}$ 1276-1279.

Paine MF, Hart HL, Ludington SS, Haining RL, Rettie AE, and Zeldin DC (2006) The human intestinal cytochrome P450 "pie". Drug Metab Dispos 34:880-886.

Piccini JP, Hasselblad V, Peterson ED, Washam JB, Califf RM, and Kong DF (2009) Comparative efficacy of dronedarone and amiodarone for the maintenance of sinus rhythm in patients with atrial fibrillation. J Am Coll Cardiol 54:1089-1095.

Pointon A, Abi-Gerges N, Cross MJ, and Sidaway JE (2013) Phenotypic profiling of structural cardiotoxins in vitro reveals dependency on multiple mechanisms of toxicity. Toxicol Sci 132 317-326.

Potente M, Fisslthaler B, Busse R, and Fleming I (2003) 11,12-Epoxyeicosatrienoic acid-induced inhibition of FOXO factors promotes endothelial proliferation by down-regulating p27Kip1. J Biol Chem 278:29619-29625.

Preissner SC, Hoffmann MF, Preissner R, Dunkel M, Gewiess A, and Preissner S (2013) Polymorphic cytochrome P450 enzymes (CYPs) and their role in personalized therapy. PLoS One 8 e82562.

Rezzani R, Giugno L, Buffoli B, Bonomini F, and Bianchi R (2005) The protective effect of caffeic acid phenethyl ester against cyclosporine A-induced cardiotoxicity in rats. Toxicology 212 $155-164$.

Saegusa K, Furukawa Y, Akahane K, Haniuda M, and Chiba S (1991) Anti-nicotinic and antimuscarinic actions of eperisone in the isolated canine atrium. Jpn J Pharmacol 56:187-193.

Seubert J, Yang B, Bradbury JA, Graves J, Degraff LM, Gabel S, Gooch R, Foley J, Newman J, Mao L, et al. (2004) Enhanced postischemic functional recovery in CYP2J2 transgenic hearts involves mitochondrial ATP-sensitive K+ channels and p42/p44 MAPK pathway. Circ Res 95: 506-514.

Spector AA, Fang X, Snyder GD, and Weintraub NL (2004) Epoxyeicosatrienoic acids (EETs): metabolism and biochemical function. Prog Lipid Res 43:55-90.

Spector AA and Norris AW (2007) Action of epoxyeicosatrienoic acids on cellular function. Am J Physiol Cell Physiol 292:C996-C1012.

Spiecker M, Darius H, Hankeln T, Soufi M, Sattler AM, Schaefer JR, Node K, Börgel J, Mügge A, Lindpaintner K, et al. (2004) Risk of coronary artery disease associated with polymorphism of the cytochrome P450 epoxygenase CYP2J2. Circulation 110:2132-2136.

Sudhahar V, Shaw S, and Imig JD (2010) Epoxyeicosatrienoic acid analogs and vascular function. Curr Med Chem 17:1181-1190.

Takemura G and Fujiwara H (2007) Doxorubicin-induced cardiomyopathy from the cardiotoxic mechanisms to management. Prog Cardiovasc Dis 49:330-352.

Tang Z, Salamanca-Pinzón SG, Wu ZL, Xiao Y, and Guengerich FP (2010) Human cytochrome P450 4F11: heterologous expression in bacteria, purification, and characterization of catalytic function. Arch Biochem Biophys 494:86-93.

Tang J, Wang G, Liu Y, Fu Y, Chi J, Zhu Y, Zhao Y, and Yin X (2011) Cyclosporin A induces cardiomyocyte injury through calcium-sensing receptor-mediated calcium overload. Die Pharmazie-An International Journal of Pharmaceutical Sciences 66(1):52-57.

Taniyama Y and Griendling KK (2003) Reactive oxygen species in the vasculature: molecular and cellular mechanisms. Hypertension 42:1075-1081.

Uehara S, Murayama N, Nakanishi Y, Nakamura C, Hashizume T, Zeldin DC, Yamazaki H, and Uno Y (2015) Immunochemical quantification of cynomolgus CYP2J2, CYP4A and CYP4F enzymes in liver and small intestine. Xenobiotica 45:124-130.

Uno Y, Hosaka S, Matsuno K, Nakamura C, Kito G, Kamataki T, and Nagata R (2007) Characterization of cynomolgus monkey cytochrome P450 (CYP) cDNAs: is CYP2C76 the only monkey-specific CYP gene responsible for species differences in drug metabolism? Arch Biochem Biophys 466:98-105.

VanAlstine MA and Hough LB (2011) Effects of acetylenic epoxygenase inhibitors on recombinant cytochrome p450s. Drug Metab Dispos 39:1221-1226.

Virkel G, Lifschitz A, Sallovitz J, Pis A, and Lanusse C (2004) Comparative hepatic and extrahepatic enantioselective sulfoxidation of albendazole and fenbendazole in sheep and cattle. Drug Metab Dispos 32:536-544.

Wang CP, Hung WC, Yu TH, Chiu CA, Lu LF, Chung FM, Hung CH, Shin SJ, Chen HJ, and Lee YJ (2010) Genetic variation in the G-50T polymorphism of the cytochrome P450 epoxygenase CYP2J2 gene and the risk of younger onset type 2 diabetes among Chinese population: potentia interaction with body mass index and family history. Exp Clin Endocrinol Diabetes 118: $346-352$.

Wang HX, Zhang DM, Zeng XJ, Mu J, Yang H, Lu LQ, and Zhang LK (2012) Upregulation of cytochrome P450 2J3/11,12-epoxyeicosatrienoic acid inhibits apoptosis in neonatal rat cardiomyocytes by a caspase-dependent pathway. Cytokine 60:360-368.

Wang SY, Xing PF, Zhang CY, and Deng BQ (2017) Association of CYP2J2 gene polymorphisms with ischemic stroke and stroke subtypes in Chinese population. Medicine (Baltimore) 96:e6266.
Wang X, Ni L, Yang L, Duan Q, Chen C, Edin ML, Zeldin DC, and Wang DW (2014) CYP2J2derived epoxyeicosatrienoic acids suppress endoplasmic reticulum stress in heart failure. $\mathrm{Mo}$ Pharmacol 85:105-115.

Wu S, Chen W, Murphy E, Gabel S, Tomer KB, Foley J, Steenbergen C, Falck JR, Moomaw CR, and Zeldin DC (1997) Molecular cloning, expression, and functional significance of a cytochrome P450 highly expressed in rat heart myocytes. J Biol Chem 272:12551-12559.

Wu S, Moomaw CR, Tomer KB, Falck JR, and Zeldin DC (1996) Molecular cloning and expression of CYP2J2, a human cytochrome $\mathrm{P} 450$ arachidonic acid epoxygenase highly expressed in heart. J Biol Chem 271:3460-3468.

Wu SN, Zhang Y, Gardner CO, Chen Q, Li Y, Wang GL, Gao PJ, and Zhu DL (2007) Evidence for association of polymorphisms in CYP2J2 and susceptibility to essential hypertension. Ann Hum Genet 71:519-525.

Wu Z, Lee D, Joo J, Shin JH, Kang W, Oh S, Lee DY, Lee SJ, Yea SS, Lee HS, et al. (2013) CYP2J2 and CYP2C19 are the major enzymes responsible for metabolism of albendazole and fenbendazole in human liver microsomes and recombinant P450 assay systems. Antimicrob Agents Chemother 57:5448-5456.

Xu D, Li N, He Y, Timofeyev V, Lu L, Tsai HJ, Kim IH, Tuteja D, Mateo RK, Singapuri A, et al. (2006) Prevention and reversal of cardiac hypertrophy by soluble epoxide hydrolase inhibitors. Proc Natl Acad Sci USA 103:18733-18738.

Xu M, Ju W, Hao H, Wang G, and Li P (2013) Cytochrome P450 2J2: distribution, function, regulation, genetic polymorphisms and clinical significance. Drug Metab Rev 45:311-352.

Xu X, Zhang XA, and Wang DW (2011) The roles of CYP450 epoxygenases and metabolites, epoxyeicosatrienoic acids, in cardiovascular and malignant diseases. Adv Drug Deliv Rev 63 597-609.

Yamagiwa T, Morita S, Amino M, Miura N, Saito T, and Inokuchi S (2014) Serum concentration of eperisone hydrochloride correlates with QT interval. Am J Emerg Med 32:75-77.

Yan H, Kong Y, He B, Huang M, Li J, Zheng J, Liang L, Bi J, Zhao S, and Shi L (2015) CYP2J2 rs890293 polymorphism is associated with susceptibility to Alzheimer's disease in the Chinese Han population. Neurosci Lett 593:56-60.

Yang L, Cheriyan J, Gutterman DD, Mayer RJ, Ament Z, Griffin JL, Lazaar AL, Newby DE, Tal-Singer R, and Wilkinson IB (2017) Mechanisms of vascular dysfunction in COPD and effects of a novel soluble epoxide hydrolase inhibitor in smokers. Chest 151:555-563.

Yang L, Ni L, Duan Q, Wang X, Chen C, Chen S, Chaugai S, Zeldin DC, Tang JR, and Wang DW (2015) CYP epoxygenase 2J2 prevents cardiac fibrosis by suppression of transmission of pro-inflammation from cardiomyocytes to macrophages. Prostaglandins Other Lipid Mediat 116-117:64-75.

Yang S, Wei S, Pozzi A, and Capdevila JH (2009) The arachidonic acid epoxygenase is a component of the signaling mechanisms responsible for VEGF-stimulated angiogenesis. Arch Biochem Biophys 489:82-91.

Yeh ET, Tong AT, Lenihan DJ, Yusuf SW, Swafford J, Champion C, Durand JB, Gibbs H, Zafarmand AA, and Ewer MS (2004) Cardiovascular complications of cancer therapy: diagnosis, pathogenesis, and management. Circulation 109:3122-3131.

Zeldin D, Wu S, and Ma J (1997a) CYP 2 J subfamily P 450 s: Physiologically relevant hemoproteins active in the metabolism of arachidonic acid in hepatic and extrahepatic tissues. Rev Toxicol 1:1-32.

Zeldin DC, Foley J, Boyle JE, Moomaw CR, Tomer KB, Parker C, Steenbergen C, and Wu S (1997b) Predominant expression of an arachidonate epoxygenase in islets of Langerhans cells in human and rat pancreas. Endocrinology 138:1338-1346.

Zeldin DC, Foley J, Ma J, Boyle JE, Pascual JM, Moomaw CR, Tomer KB, Steenbergen C, and Wu S (1996) CYP2J subfamily P450s in the lung: expression, localization, and potential functional significance. Mol Pharmacol 50:1111-1117.

Zhang G, Panigrahy D, Hwang SH, Yang J, Mahakian LM, Wettersten HI, Liu JY, Wang Y, Ingham ES, Tam S, et al. (2014) Dual inhibition of cyclooxygenase-2 and soluble epoxide hydrolase synergistically suppresses primary tumor growth and metastasis. Proc Natl Acad Sci USA 111:11127-11132.

Zhang LN, Vincelette J, Cheng Y, Mehra U, Chen D, Anandan SK, Gless R, Webb HK, and Wang YX (2009a) Inhibition of soluble epoxide hydrolase attenuated atherosclerosis, abdominal aortic aneurysm formation, and dyslipidemia. Arterioscler Thromb Vasc Biol 29:1265-1270.

Zhang QY, Ding X, and Kaminsky LS (1997) CDNA cloning, heterologous expression, and characterization of rat intestinal CYP2J4. Arch Biochem Biophys 340:270-278.

Zhang Y, El-Sikhry H, Chaudhary KR, Batchu SN, Shayeganpour A, Jukar TO, Bradbury JA, Graves JP, DeGraff LM, Myers P, et al. (2009b) Overexpression of CYP2J2 provides protection against doxorubicin-induced cardiotoxicity. Am J Physiol Heart Circ Physiol 297:H37-H46.

Zhou JM, Xu ZL, Li N, Zhao YW, Wang ZZ, and Xiao W (2016) Identification of cardioprotective agents from traditional Chinese medicine against oxidative damage. Mol Med Rep 14:77-88.

Zhou Z, Vorperian VR, Gong Q, Zhang S, and January CT (1999) Block of HERG potassium channels by the antihistamine astemizole and its metabolites desmethylastemizole and norastemizole. J Cardiovasc Electrophysiol 10:836-843.

Zhu Q, Fu Z, Ma Y, Yang H, Huang D, Xie X, Liu F, Zheng Y, and Cha E (2013) A novel polymorphism of the CYP2J2 gene is associated with coronary artery disease in Uygur population in China. Clin Biochem 46:1047-1054.

Zordoky BN, Anwar-Mohamed A, Aboutabl ME, and El-Kadi AO (2010) Acute doxorubicin cardiotoxicity alters cardiac cytochrome P450 expression and arachidonic acid metabolism in rats. Toxicol Appl Pharmacol 242:38-46.

Zordoky BN and El-Kadi AO (2008a) Modulation of cardiac and hepatic cytochrome P450 enzymes during heart failure. Curr Drug Metab 9:122-128.

Zordoky BN and El-Kadi AO (2008b) Induction of several cytochrome P450 genes by doxorubicin in H9c2 cells. Vascul Pharmacol 49:166-172.

Address correspondence to: Meetal Solanki, Department of Cardiovascular Sciences, University of Leicester, Clinical Sciences, Glenfield Hospital, Leicester LE3 9QP, United Kingdom. E-mail: mss35@le.ac.uk 